\title{
Stimulus complexity and categorical effects in human auditory cortex: an Activation Likelihood Estimation meta-analysis
}

\author{
Fabienne Samson ${ }^{1,2 *}$, Thomas A. Zeffiro ${ }^{3}$, Alain Toussaint ${ }^{1,2}$ and Pascal Belin ${ }^{4,5}$ \\ 1 Centre d'Excellence en Troubles Envahissants du Développement de I'Université de Montréal, Montréal, OC, Canada \\ 2 Centre de Recherche Fernand-Seguin, Department of Psychiatry, Université de Montréal, Montréal, OC, Canada \\ 3 Neural Systems Group, Massachusetts General Hospital, Boston, MA, USA \\ ${ }^{4}$ Institute of Neuroscience and Psychology, University of Glasgow, Glasgow, Scotland, UK \\ ${ }_{5}$ International Laboratories for Brain, Music and Sound, McGill University and Université de Montréal, Montréal, QC, Canada
}

\section{Edited by:}

Josef P. Rauschecker, Georgetown University School of Medicine, USA

\section{Reviewed by:}

Jonas Obleser, Max Planck Institute for Human Cognitive and Brain Sciences,

Germany

Josef P. Rauschecker, Georgetown

University School of Medicine, USA

\section{*Correspondence:}

Fabienne Samson, Hôpital Rivière-desPrairies, RechercheTN, 7070 Boulevard Perras, Montréal, OC, Canada H1E 1A4. e-mail:samsonfabienne1@gmail.com
Investigations of the functional organization of human auditory cortex typically examine responses to different sound categories. An alternative approach is to characterize sounds with respect to their amount of variation in the time and frequency domains (i.e., spectral and temporal complexity). Although the vast majority of published studies examine contrasts between discrete sound categories, an alternative complexity-based taxonomy can be evaluated through metaanalysis. In a quantitative meta-analysis of 58 auditory neuroimaging studies, we examined the evidence supporting current models of functional specialization for auditory processing using grouping criteria based on either categories or spectro-temporal complexity. Consistent with current models, analyses based on typical sound categories revealed hierarchical auditory organization and left-lateralized responses to speech sounds, with high speech sensitivity in the left anterior superior temporal cortex. Classification of contrasts based on spectro-temporal complexity, on the other hand, revealed a striking within-hemisphere dissociation in which caudolateral temporal regions in auditory cortex showed greater sensitivity to spectral changes, while anterior superior temporal cortical areas were more sensitive to temporal variation, consistent with recent findings in animal models. The meta-analysis thus suggests that spectro-temporal acoustic complexity represents a useful alternative taxonomy to investigate the functional organization of human auditory cortex.

Keywords: fMRI, category, time, frequency, hierarchy

\section{INTRODUCTION}

Current accounts of the functional organization of auditory cortex, mostly based on response specificity to different sound categories, describe an organizational structure that is both hierarchical and hemispherically specialized (Rauschecker, 1998; Zatorre et al., 2002; Hackett, 2008; Rauschecker and Scott, 2009; Woods and Alain, 2009; Recanzone and Cohen, 2010).

Characterizing responses to stimuli from typical auditory categories such as music, voices, animal, or environmental sounds have provided important information about the cortical specialization for auditory processing. However, this classification may not fully account for the range of stimulus variability encountered across neuroimaging studies, as most stimuli do not fit neatly into one auditory category. For instance, an amplitude modulated tone can vary in ways that cannot be adequately characterized using typical categories. However, its characteristics can easily be described in terms of variations in time (temporal dimension) and frequency (spectral dimension), suggesting an alternative approach to stimulus classification. Accordingly, any auditory stimulus can be described with respect to its sound complexity characteristics specified with respect to changes in time and frequency. This approach represents a comprehensive characterization of sounds that is not limited to specific categories. Therefore, complexity might represent an alternative organizing principle along which to represent auditory cortical response specialization. In this conceptualization, a single frequency sinusoidal wave (pure tone), constant over time, can be classified as simple, and a sound containing multiple components can be classified as complex with respect to the frequency domain. Examples of sounds with high spectral complexity are musical notes or sustained vowels. Similarly, a sound with acoustical structure varying over time can be classified as complex with respect to the time domain. Examples of stimuli with high temporal complexity are frequency or amplitude modulated sounds or sound sequences. Natural sounds can be complex with regards to both their frequency composition and temporal variation. Phonemes, the basic units of speech, contain multiple frequency components, called formants, which may be combined over time to produce syllables and words. Similarly, musical sequences are composed of complex changes in fundamental frequency and harmonic structure that unfold over time. Additionally, speech processing is mainly dependent on temporal information (Shannon et al., 1995), while spectral composition is most relevant for music perception (Warrier and Zatorre, 2002). Hence, acoustic complexity is not independent of sound categories and the two classification methods explored here should not be considered as mutually exclusive.

As previously proposed, an auditory stimulus can be categorized in more than one way; either based on a priori knowledge about the characterizing features of the sound source or on the basis of a sound's acoustic pattern in the frequency and time domain (Griffiths and Warren, 2004). Additionally, some studies suggest 
that auditory cortex activation to sounds of a given category could reflect a specialized response to the acoustic components characterizing sounds within this category (Lewis et al., 2005, 2009). This suggests a certain level of interaction between the cortical processes involved in the analysis of acoustic features and those showing sensitivity to sound categories. However, recently Leaver and Rauschecker (2010) demonstrated categorical effects of speech and music stimuli even when controlling for changes in spectral and temporal dimensions. The two classification approaches are therefore not mutually exclusive and both methods seem relevant and can complement each other in revealing different aspects of cortical auditory specialization. In vision, cortical representation of stimulus complexity has been described with simple (first-order) information being analyzed within primary visual cortex (V1) and complex (second-order) information processing involving both primary and non-primary visual cortex (V2/V3; Chubb and Sperling, 1988; Larsson et al., 2006). Given that parallels have often been drawn between visual and auditory cortical functional organization (Rauschecker and Tian, 2000), we were interested in examining how well characterization of sounds by their acoustic complexity might reflects new insights into regional functional specialization.

Given that auditory neuroimaging studies exhibit a high degree of stimulus and task heterogeneity, their individual cortical activity patterns are not easily integrated to obtain an unambiguous picture of typical human auditory cortical organization. Neuroimaging meta-analysis offers a potential solution to this problem as it estimates the consistency of regional brain activity across similar stimuli and tasks, providing a quantitative summary of the state of research in a specific cognitive domain (Fox et al., 1998), estimating the replicability of effects across different scanners, tasks, stimuli, and research groups. By revealing consistently activated voxels across a set of experiments, meta-analysis can characterize the cortical response specificity associated with a particular type of task or stimulus (Wager et al., 2009). Activation Likelihood Estimation (ALE) is a voxel-wise meta-analysis method that provides a quantitative summary of task-related activity consistency across neuroimaging studies (Turkeltaub et al., 2002).

In the current study, we use quantitative ALE meta-analysis to examine the spatial consistency of human auditory processing, classified using either conventional sound categories or acoustic complexity. Given the focus of our study on stimulus complexity effects, we excluded studies of spatial auditory processes including localization, and inter-aural delay, as well as those including complex tasks.

First, we classified sounds using typical auditory categories to examine the evidence supporting hierarchically and hemispherically lateralized functional organization for auditory cortical processing. Hierarchical auditory processing has been described as sensitivity to stimulus complexity increasing from primary to non-primary auditory cortex, with simpler perceptual features represented at primary levels (Wessinger et al., 2001; Hall et al., 2002; Scott and Johnsrude, 2003). Relative hemispheric specialization is reflected by predominantly left-hemisphere processing for speech sounds and stronger right-hemisphere responses to music (for a review see Zatorre et al., 2002). We used typical sound categories, such as pure tones, noise, music, and vocal sounds, to classify auditory material to see if simple sound processing is associated with activity in primary auditory cortex while complex sound processing is associated with activity including both primary and non-primary auditory cortex. We were also interested in examining whether there was meta-analytic evidence for distinctive patterns of hemispheric specialization for music and vocal sounds.

Next, we more closely examined vocal stimuli and a particular subcategory of vocal sounds: intelligible speech. Vocalizations constitute an ecologically central sound category that includes all sounds with a vocal quality irrespective of phonetic or lexical content. Examples include speech in various languages, non-speech affective vocalizations (e.g., laughter), and laboratory-engineered sounds, such as time-reversed speech, that exhibit distinctly vocal qualities. Vocal sounds include, but are not limited to, intelligible speech. Based on previous findings, we expected to observe bilateral superior temporal gyrus (STG) and the superior temporal sulcus (STS) activity related to vocal sounds (Belin et al., 2000, 2002; Kriegstein and Giraud, 2004), and anterior STG and STS activity on the left related to speech intelligibility (Benson et al., 2006; Uppenkamp et al., 2006).

Finally, we examined whether acoustic complexity, estimated from variations in time (temporal) and frequency (spectral) dimensions, represents a relevant organizing principle for functional response specificity in human auditory cortex. In terms of spectral composition, stimuli can have single or multiple frequency components. In the temporal dimension, stimuli can be characterized as unchanging or, for those containing temporal changes, having either regular or irregular changes. Using this classification, we characterized the cortical response related to each level of acoustic complexity. Then, by comparing the "multiple" to the "single" categories, independent of the temporal changes, and the "changing" to the "unchanging" categories, independent of the spectral composition, we isolated the cortical activity related to variations in the frequency and time dimensions, respectively.

\section{MATERIALS AND METHODS INCLUSION OF STUDIES}

A preliminary list of articles was identified using several Medline database searches including both articles published prior to March 2010 [keywords: positron emission tomography (PET), functional magnetic resonance imaging ( $\mathrm{fMRI}$ ), auditory, sound, hear*, speech, and music] and lists of citations within those articles. Studies were included if they fulfilled specific inclusion criteria: (1) the study was published in a peer-reviewed journal; (2) the study involved a group of healthy typical adult participants with no history of hearing, psychiatric, neurological, or other medical disorders, (3) the subjects were not trained musicians; (4) the auditory stimuli were delivered binaurally, with no inter-aural delay because of our focus on non-spatial auditory processing; (5) the task-related activity coordinates were reported in standardized anatomical space; (6) the study used whole-brain imaging and voxel-wise analysis. As our main goal was to determine the spatial distribution within auditory cortical regions, the few studies using incomplete brain coverage, but that included the temporal cortex were not excluded (Binder et al., 1996, 2000; Belin et al., 1999; Celsis et al., 1999; Hugdahl et al., 2003; Stevens, 2004; Schönwiesner et al., 2005; Zaehle et al., 2007). Additionally, some studies specifically included subcortical structures (Griffiths et al., 1998; Hwang et al., 2007; Mutschler 
et al., 2010); and (7) the study had to include passive listening or a simple response task, such as a button press at the end of each sound to assess the participants' attentive state, task characteristics that tended to minimize the inclusion of activity related to top-down processes or task difficulty (Dehaene-Lambertz et al., 2005; Dufor et al., 2007; Sabri et al., 2008).

Of over 7000 articles retrieved, 58 (19 PET and 39 fMRI) satisfied all inclusion criteria and were included in the analysis (Table 1). Several studies reported activity from multiple task and control conditions. For our analysis, only conditions incorporating either no overt task or a simple task used to maintain attention were considered. To maintain consistency among the control conditions, only task contrasts with a low-level baseline (silence, tone, or noise) were included. For some studies, more than one contrast satisfied our criteria and all were included in the analysis. This procedure was employed to maximize the sensitivity of the analysis, but could potentially bias the results toward samples for which more than one contrast was included.

\section{CONTRAST CLASSIFICATION PROCEDURE}

One hundred seventeen contrasts, including 768 foci, met the inclusion criteria. These contrasts were classified first by typical sound categories and then according to their variation along either the frequency or time dimension (Table 1).

For the first method, each contrast was classified with respect to one of the typical sound categories: simple sounds or pure tones ( 9 contrasts, 22 foci), noise ( 4 contrasts, 31 foci), music (10 contrasts, 175 foci), and vocal sounds ( 62 contrasts, 370 foci). The pure tones category included only contrasts of single tones vs. silence; the noise category included white, pink, and brown noise (Rimol et al., 2005), noise bursts (Zatorre et al., 1992), and the combination of multiple reversed environmental sounds (Zatorre et al., 2002). Melodies, notes, chords, and chord progressions were classified as music. Finally, all sounds with a vocal quality (syllables, words, voices, reversed words, or pseudowords) were included in the vocal sounds category. Ideally, we would have included other commonly used sound categories such as animal or environmental sounds; however the number of contrasts falling into these categories was not sufficient for quantitative meta-analysis, with only one contrast presenting environmental sounds and only two falling into the animal sound category. The remaining contrasts (30/117), including modulated tones, frequency sweep, harmonic tones, or recorded noise, were not included in this analysis because they did not neatly fit into one sound category.

For the second method, we classified the stimuli with respect to their acoustic features. Two levels of complexity were defined using the frequency dimension (single and multiple frequency components) and three levels in the time domain (unchanging, regular periodic change, or irregular change). Therefore, task contrasts were classified in one of six complexity levels depending on their frequency- and time-related acoustic features (Table 1; Figure 5A): (1) "single, unchanging" (single tone; 9 contrasts, 22 foci), (2)“single, regular change" (frequency or amplitude modulated tone, single formant frequency sweep, parametric variation of modulation rate or rate of presentation; 8 contrasts, 38 foci), (3) "single, irregular change" ( 1 contrast, 4 foci), (4) "multiple, unchanging" (harmonic tone, square wave tone, vowel, noise, or parametrically increasing spectral component numbers; 10 contrasts, 57 foci), (5) "multiple, regular change" (tone sequences and increasing click rate sequences; 6 contrasts, 41 foci), or (6) "multiple, irregular change" (vocal sounds, music, or environmental sounds; 70 contrasts, 517 foci). Each task contrast was classified using the stimulus description provided in each study. Contrasts resulting from covariate effects of a parameter of interest were classified according to parameter complexity. For instance, effects related to parametric increases in temporal modulation rate were assigned to the "single, regular change” complexity level (Schönwiesner et al., 2005). Ambiguous contrasts were excluded from analysis. For example, we did not classify contrasts that used comparison stimuli that had acoustic complexity comparable to the stimuli of interest (Zatorre et al., 1994; Griffiths et al., 1998; Blood et al., 1999; Mummery et al., 1999; Warren and Griffiths, 2003; Giraud et al., 2004; Schwarzbauer et al., 2006; Peretz et al., 2009) nor those using stimuli that could be assigned to more than one complexity level, such as notes, chords, or chord progressions (i.e., stimuli including note/chord/chord progression; Benson et al., 2001).

\section{ALE META-ANALYSIS}

After the task-related activity maxima were classified, ALE maps (Turkeltaub et al., 2002) were computed using GingerALE 1.1 (Laird et al., 2005). Coordinates reported in MNI space were converted to Talairach space using the Lancaster transform icbm2tal (Lancaster et al., 2007). ALE models uncertainty in localization of each activation focus as a Gaussian probability distribution, yielding a statistical map in which each voxel value represents an estimate of the likelihood of activity at that location, utilizing a fixed effects model for which inferences should be limited to the studies under examination. Critical thresholds for the ALE maps were determined using a Monte Carlo style permutation analysis of sets of randomly distributed foci. A FWHM of $10 \mathrm{~mm}$ was selected for the estimated Gaussian probability distributions. Critical thresholds were determined using 5000 permutations, corrected for multiple comparisons ( $p<0.01$ false discovery rate, FDR; Laird et al., 2005) with a cluster extent of greater than $250 \mathrm{~mm}^{3}$. In order to present results in the format most commonly used in the current literature, the ALE coordinate results were transformed into MNI standard space using the Lancaster transform (Lancaster et al., 2007), while ALE maps were transformed by applying spatial normalization parameters obtained from mapping from Talairach to MNI space.

\section{ANALYSIS USING CLASSIFICATION BY TYPICAL AUDITORY CATEGORIES}

First, ALE maps were computed for each of the four typical auditory categories: pure tones, noise, music and vocal sounds. Each resulting map shows regions exhibiting consistent activity across studies for each sound category. For example, the "music" map shows the voxel-wise probability of activity for all "musical stimuli vs. baseline" contrasts.

Next, we examined hemispheric specialization effects by directly comparing the "music" and "vocal" sound categories. We directly compared a random subsample of the "vocal" sounds category (Table A1 in Appendix; 20 contrasts, 156 foci) to the "music" category ( 10 contrasts, 175 foci). This procedure ensured that the resulting ALE maps would reflect activity differences between studies rather than the imbalance in coordinate numbers 


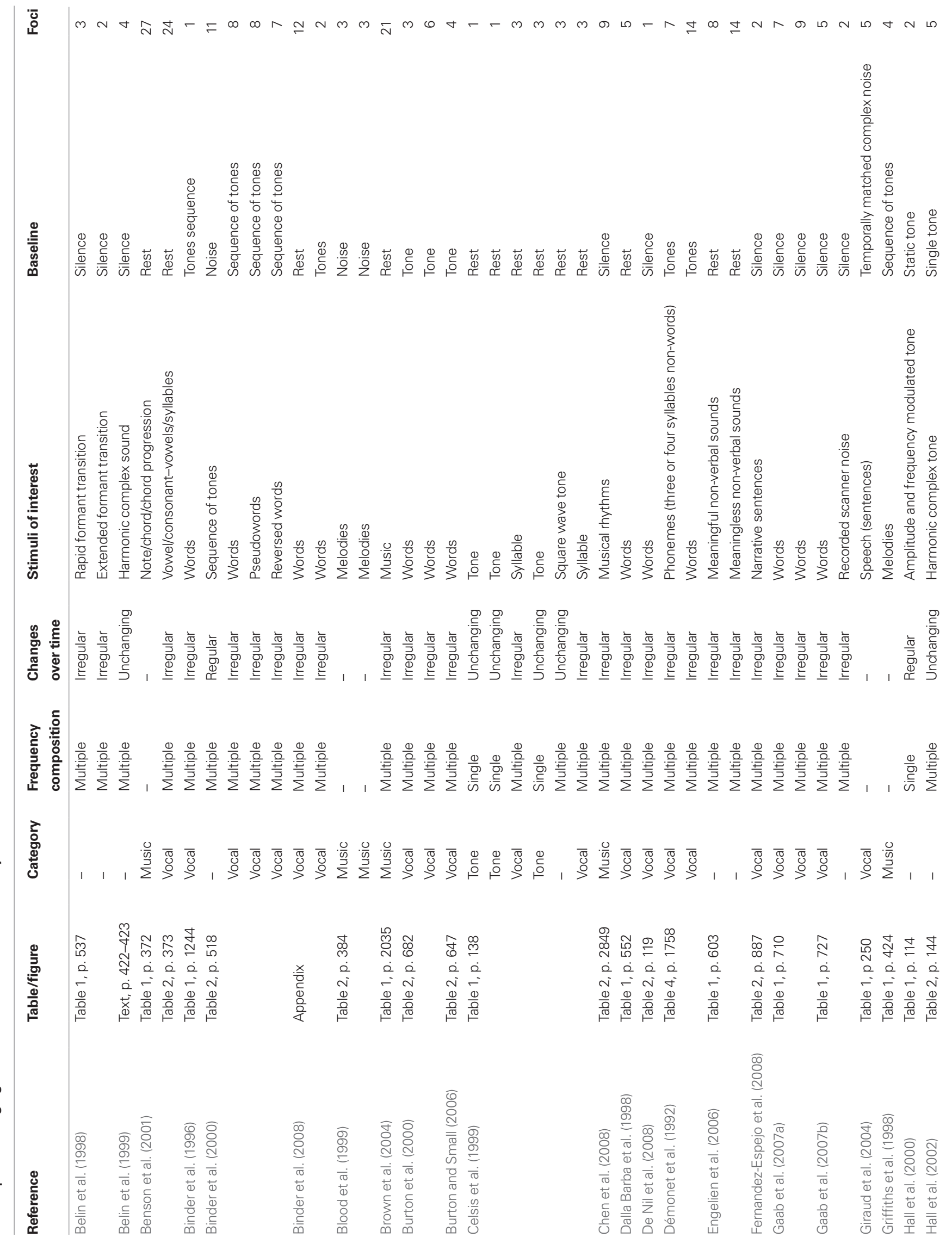




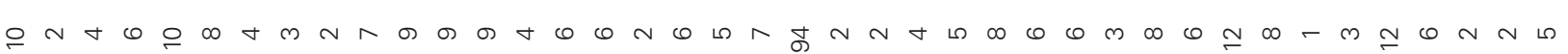
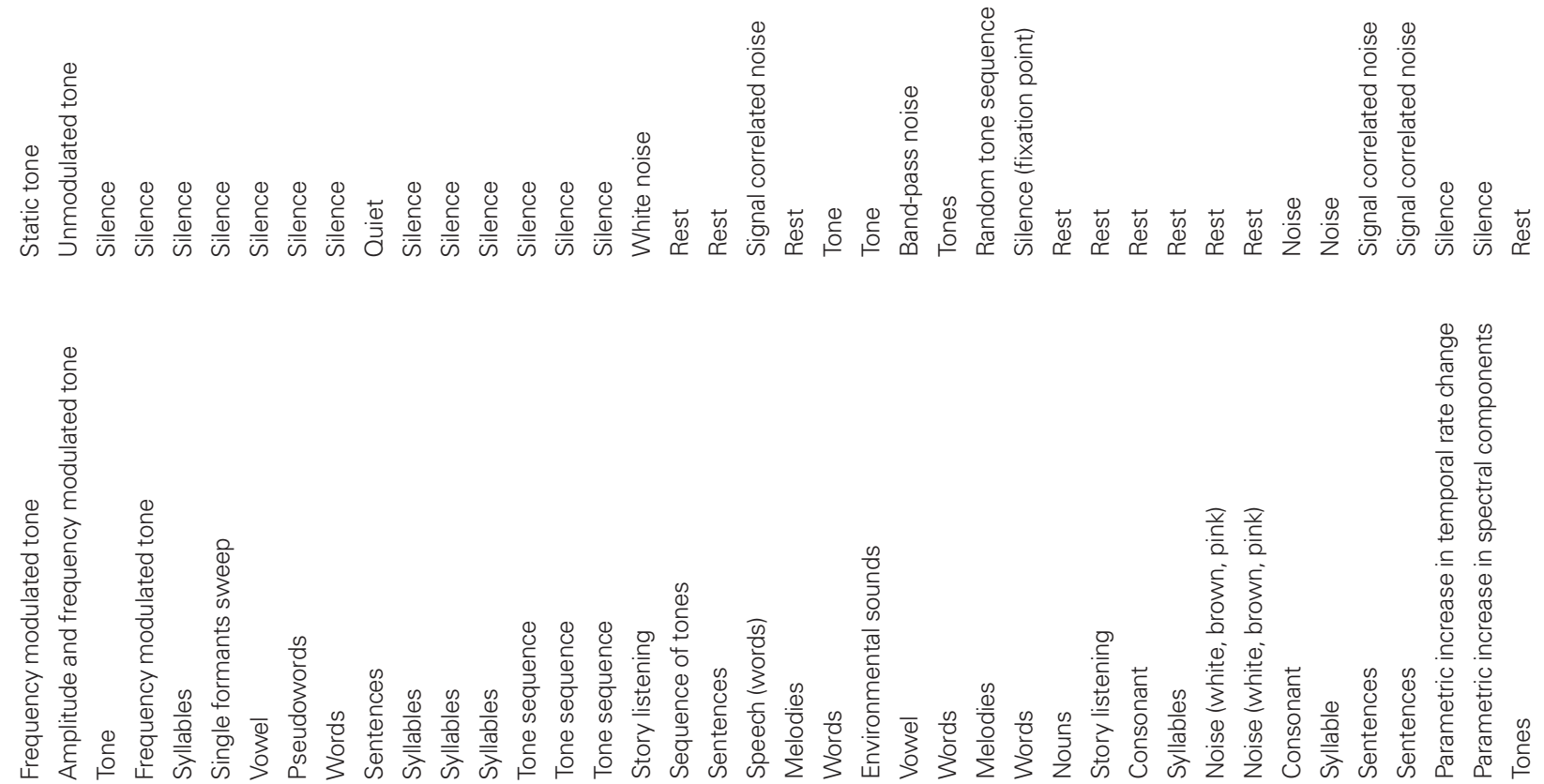

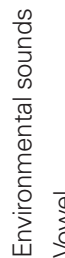

善 $\frac{\bar{c}}{2}$

起产

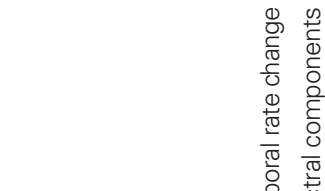

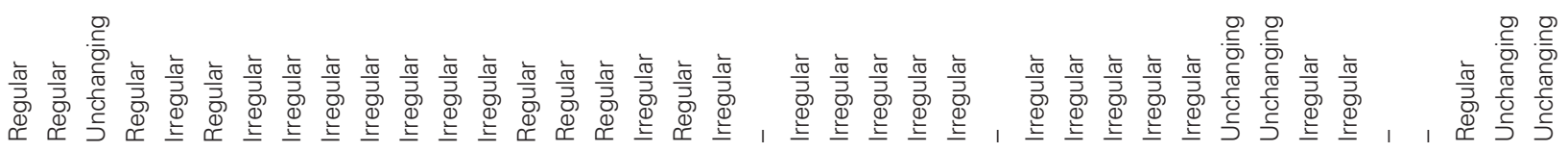

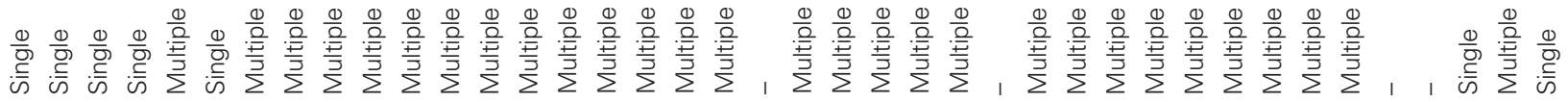

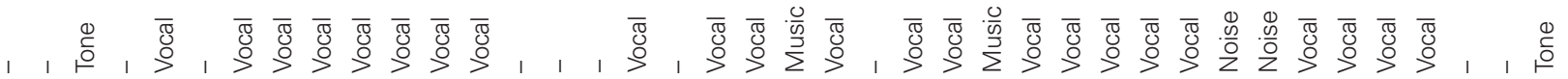

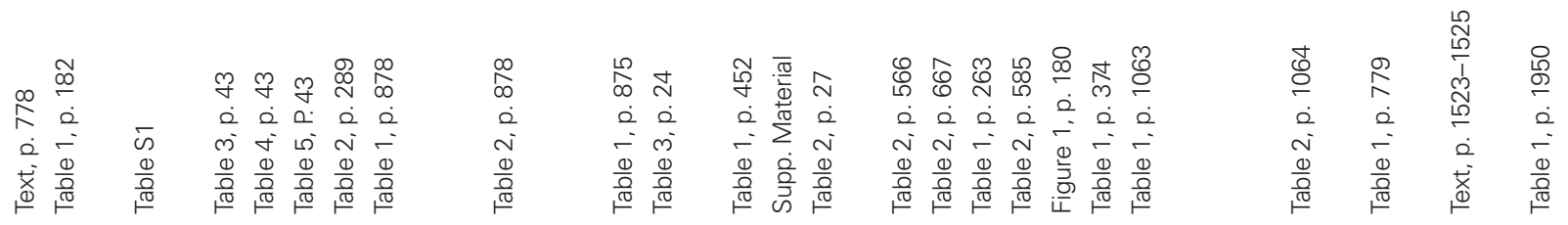

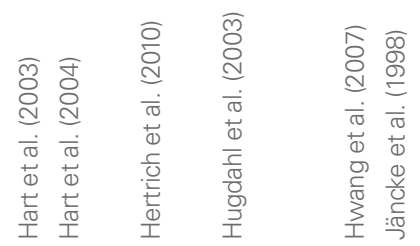

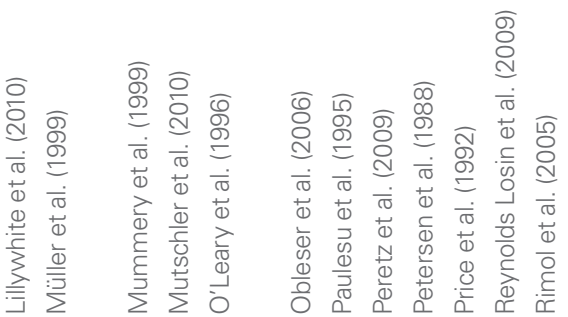

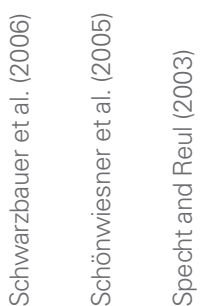




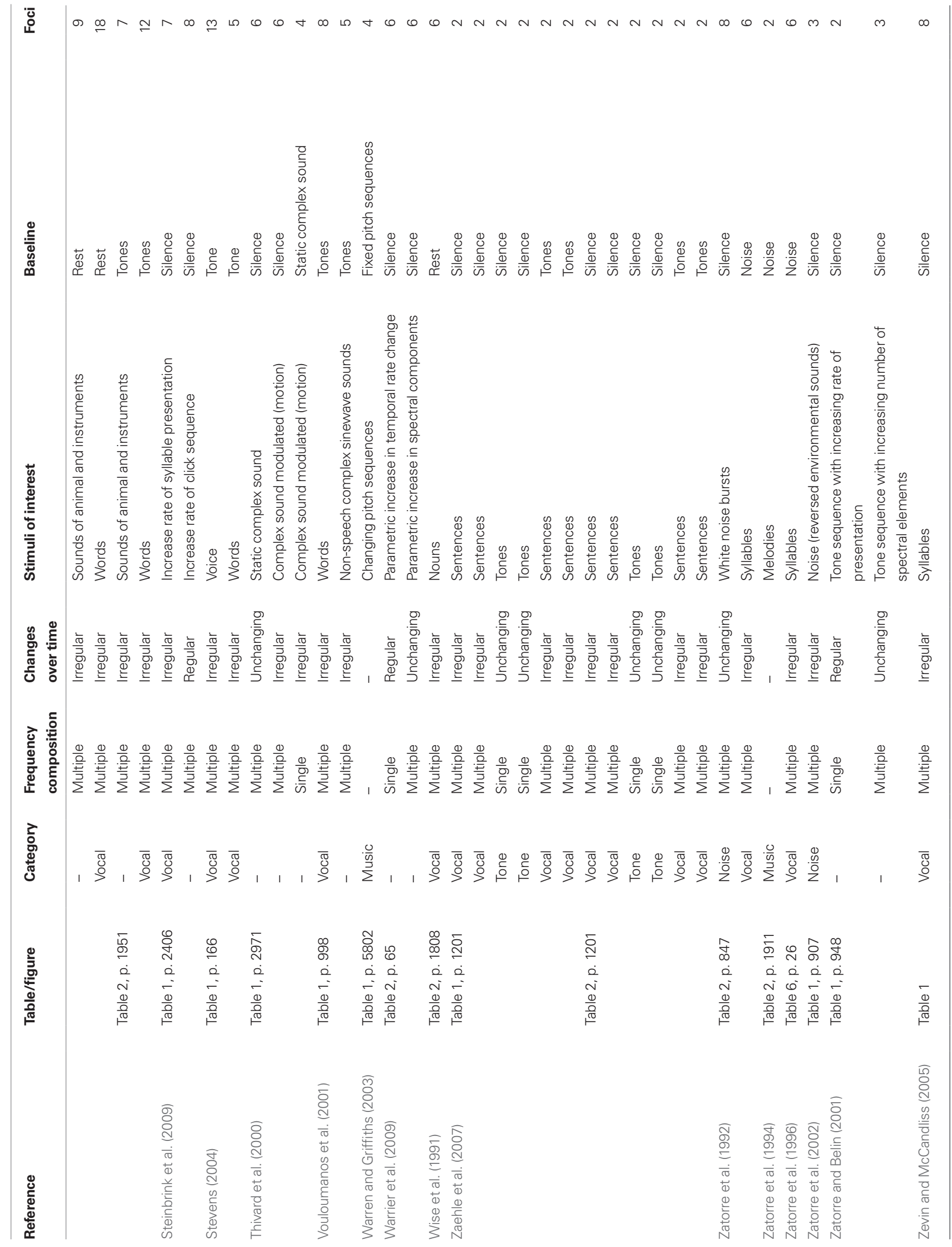


between those categories (Laird et al., 2005). Then, as lateralization effects are reported for intelligible speech rather than vocal sounds, only contrasts using intelligible speech with semantic content, such as words or sentences, were included. The "music" and the "speech" categories were directly compared to investigate the expected lateralization effects. Given that many contrasts fell into the intelligible speech category, we selected only one contrast per study (Table A1 in Appendix), including a total of 27 contrasts (166 foci).

Finally, we assessed cortical auditory specialization for processing intelligible speech. Given that specialized auditory processes can be more easily isolated when the contrasting stimuli are as close as possible to the stimuli of interest in terms of acoustic complexity (Binder et al., 2000; Uppenkamp et al., 2006), contrasts containing unintelligible spectrally and temporally complex sounds were used as for comparison. Thirteen contrasts (76 foci, see Table A1 in Appendix) selected included reversed words, pseudowords, recorded scanner noise, single formant, environmental sounds, and modulated complex sounds. We directly compared the intelligible speech and complex nonspeech sound categories.

\section{ANALYSIS USING CLASSIFICATION BY AUDITORY COMPLEXITY}

To investigate the relevance of acoustic complexity as a stimulus property predicting functional auditory specialization, we computed ALE maps for each level of complexity. Given that only one contrast fell into the "single, irregular change" dimension, this analysis was not conducted. Moreover, as most of the contrasts were classified as "multiple frequencies, irregular modulation" (70 contrasts, 517 foci), a randomly selected subsample of 10 contrasts (70 foci, see Table A1 in Appendix) were selected from this level of complexity to facilitate comparison of activity extent between levels.

Next, we examined effects related to auditory complexity. For the frequency domain, all contrasts falling in the "multiple" level (26 contrasts, 168 foci) were directly compared to those in the "single" level (18 contrasts, 64 foci), independent of their variation over time, (Figure 5A, bottom row vs. top row, green arrow). For the time dimension, comparisons were made between the contrasts including stimulus changes over time (regular and irregular; 25 experiments, 153 foci) and those who did not (unchanging; 19 contrasts, 79 foci), independent of their frequency composition (Figure 5A, middle and right column vs. left column, blue arrow).

\section{RESULTS}

\section{STIMULUS CLASSIFICATION USING TYPICAL AUDITORY CATEGORIES}

We observed different patterns of activity corresponding to the typical sound categories of pure tones, noise, music, and vocal sounds (Figure 1; Table 2). For all the categories, the strongest effects were found in auditory cortex (Brodmann areas 41, 42, and 22 ). For the pure tone map, high ALE values were found bilaterally in medial Heschl's gyri (HG). The noise map revealed effects in right medial HG and bilaterally in STG posterior and lateral to HG. Effects related to music were seen in $\mathrm{HG}$, anterior and posterior STG. Finally, vocal sounds elicited large bilateral clusters of activity in HG as well as anterior, posterior, and lateral aspects of the STG. While pure tone effects were restricted to auditory cortex, effects outside temporal cortex were observed for the other categories. Additional activity was seen in frontal cortex for noise (BA 6, 9),

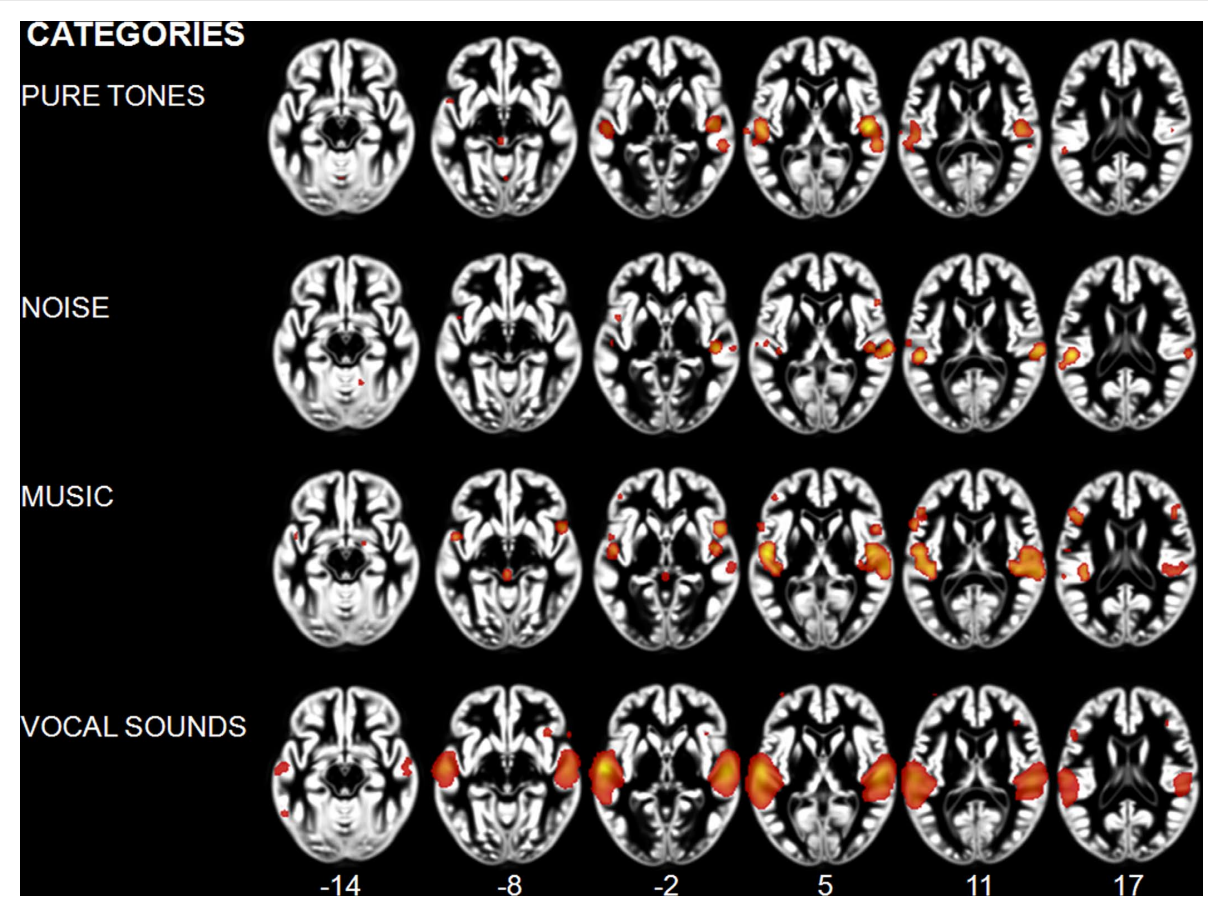

FIGURE 1 |Activation Likelihood Estimation maps showing clusters of activity related to sound categories: pure tones, noise, music, and vocal sounds. Maps are superimposed on an anatomical template in MNI space. Axial images are shown using the neurological convention with MNI z-coordinate labels $\left(p_{\mathrm{FDR}}<0.01\right)$. 


\begin{tabular}{|c|c|c|c|c|c|c|}
\hline \multirow[b]{2}{*}{ Region } & \multirow[b]{2}{*}{ BA } & \multicolumn{3}{|c|}{ Coordinates } & \multirow[b]{2}{*}{ Volume $\left(\mathrm{mm}^{3}\right)$} & \multirow[b]{2}{*}{$\operatorname{ALE}\left(\times 10^{-3}\right)$} \\
\hline & & $x$ & $y$ & $z$ & & \\
\hline \multicolumn{7}{|l|}{ PURETONES } \\
\hline \multicolumn{7}{|l|}{ Temporal } \\
\hline Heschl's gyrus & 41 & 53 & -17 & 1 & 3864 & 26.00 \\
\hline Heschl's gyrus & 41 & -51 & -20 & 1 & 2600 & 16.85 \\
\hline \multicolumn{7}{|l|}{ Temporal } \\
\hline Superior temporal gyrus & 22 & 68 & -23 & 5 & 1544 & 12.98 \\
\hline Superior temporal gyrus & 42 & -50 & -29 & 15 & 1384 & 15.58 \\
\hline Superior temporal gyrus & 22 & 51 & -24 & -1 & 648 & 11.30 \\
\hline \multicolumn{7}{|l|}{ Frontal } \\
\hline Cerebellum & & 33 & -65 & -28 & 360 & 7.83 \\
\hline \multicolumn{7}{|l|}{ MUSIC } \\
\hline \multicolumn{7}{|l|}{ Temporal lobe } \\
\hline Superior temporal gyrus & 22 & 53 & -11 & 2 & 6744 & 21.07 \\
\hline Superior temporal gyrus & 22 & -51 & -12 & -7 & 4848 & 28.52 \\
\hline Superior temporal gyrus & 22 & 55 & 12 & -9 & 1096 & 18.21 \\
\hline Superior temporal gyrus & 22 & -49 & 3 & -13 & 256 & 11.58 \\
\hline \multicolumn{7}{|l|}{ Frontal lobe } \\
\hline Inferior frontal gyrus & 45 & 51 & 34 & 18 & 1264 & 14.91 \\
\hline Inferior frontal gyrus & 45 & -42 & 24 & 12 & 1240 & 14.04 \\
\hline Superior temporal gyrus & 22 & -59 & -12 & -5 & 22648 & 134.64 \\
\hline Superior temporal gyrus & 22 & 62 & -13 & -4 & 18088 & 101.69 \\
\hline \multicolumn{7}{|l|}{ Frontal } \\
\hline Inferior frontal gyrus & 45 & -48 & 17 & 26 & 2112 & 21.16 \\
\hline \multicolumn{7}{|l|}{ Limbic } \\
\hline Cingulate gyrus & 24 & -5 & 13 & 46 & 584 & 18.72 \\
\hline
\end{tabular}

MNI coordinates of the locations of significant ALE maxima for each sound category $(p<0.01, k=250$ voxels $)$.

music (BA 4, 6, 44, 45, 46), and vocal sounds (BA 45). Effects were observed in cerebellum for noise and music as well as in the anterior cingulate gyrus for vocal sounds.

Effects related to typical sound categories were lateralized. Qualitative examination revealed larger clusters in right auditory cortex for music and in left auditory cortex for vocal sounds (Table 2). The direct comparisons between the musical and vocal sounds and between the musical and speech sounds yielded similar findings (Figure 2; Table 3). Greater activity related to music was observed bilaterally in posterior and anterolateral $\mathrm{HG}$, the planum polare, and the most anterior parts of the right STG. We also observed effects related to music processing outside the temporal lobe, in inferior frontal gyrus (BA 45), the middle frontal gyrus (BA 6), and the left cerebellum (lobule IV). On the other hand, the reverse comparisons revealed stronger activity for vocal sounds as well as for speech in lateral HG, extending to lateral and anterior STG. For the vocal sounds, the extent of auditory activity was greater on the left (10312 voxels) than on the right (4952 voxels), however the ALE values were similar on the left $\left(45.66 \times 10^{-3}\right)$ and on the right $\left(42.24 \times 10^{-3}\right)$. As for the speech sounds, both the volume of activity and the corresponding ALE were greater on the left $\left(11112\right.$ voxels, $\left.61.39 \times 10^{-3}\right)$ than the right ( 5736 voxels, $38.21 \times 10^{-3}$ ) hemisphere. 


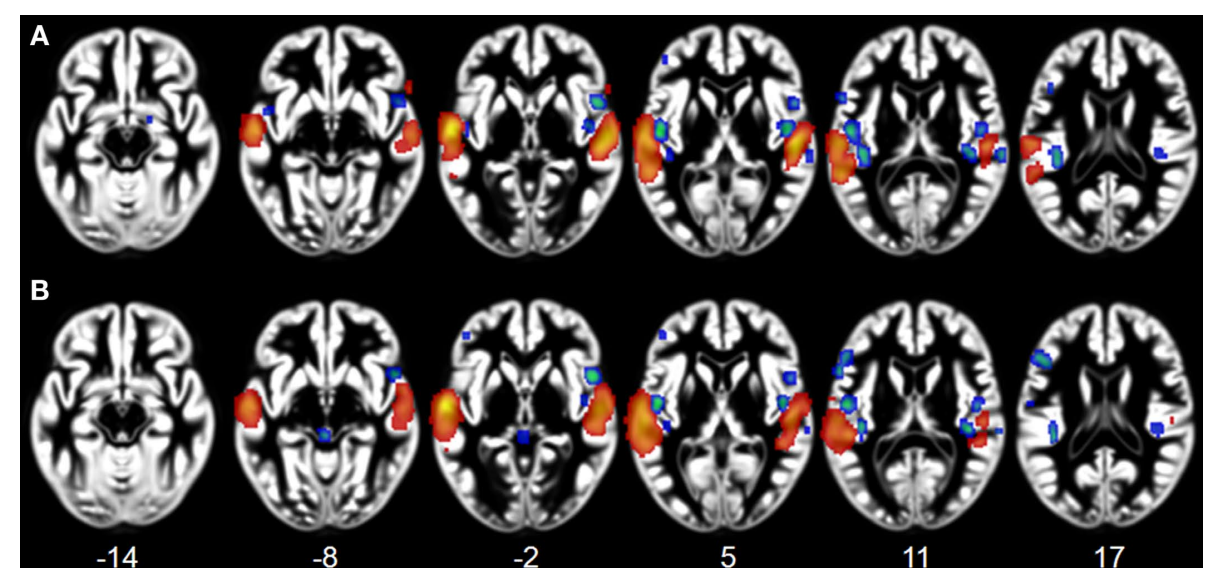

FIGURE 2 | Activation Likelihood Estimation maps showing lateralization effects for (A) voices > music (RED-YELLOW) and music > voices (BLUE-GREEN) comparisons and for (B) speech > music (RED-YELLOW) and music > speech (BLUE-GREEN) comparisons. Maps are superimposed on an anatomical template in $\mathrm{MNI}$ space. Axial images are shown using the neurological convention with $\mathrm{MNI} z$-coordinate labels $\left(p_{\mathrm{FDR}}<0.01\right)$.

We observed specialization for speech processing in auditory cortex. The comparison between intelligible speech and complex nonspeech sounds, including vocal sounds without intelligible content, is shown in Table 4 and Figure 3A. Speech was associated with greater activity in non-primary (BA 22) and associative (BA 39) auditory areas, lateral STG, bilateral anterior and middle STS, and the planum temporale (PT). These clusters were larger and had higher ALE values in the left hemisphere. We also observed stronger left prefrontal cortical activity (BA 8) for speech sounds. The reverse comparison yielded stronger activity related to complex non-speech sounds in the right PT ( $x=68, y=-27, z=8,128$ voxels; Figure 3A). The ALE maps associated with speech intelligibility had overlap with the vocal sound category maps (Figure 3B). While large bilateral clusters were observed along the STG and STS for the vocal sounds, there was specific sensitivity to speech intelligibility in the left anterior STG.

\section{STIMULUS CLASSIFICATION USING AUDITORY COMPLEXITY}

Classification of sounds with respect to their spectral and temporal complexity revealed effects in the temporal lobe (Table 5; Figure 4). The "single, unchanging" stimulus class was associated with two clusters centered on medial HG (BA 41). The "single, regular change" stimulus class was associated with two large bilateral clusters of activity in medial and lateral HG, extending around HG into the anterolateral STG. On the left, we observed one additional peak of activity in posterior STG. For the "multiple, unchanging" stimulus class, temporal lobe activity was centered on medial HG and posterior STG. Effects for the "multiple, regular change" stimulus class were observed in HG, extending to the posterolateral STG. Finally, the "multiple, irregular change" stimulus class was associated with large bilateral effects in, and posterior to, HG. The complexity level maps revealed effects outside the temporal lobe, in frontal cortex areas BA 6, 9, 36, and 47 for the "multiple, unchanging" and "multiple, regular change" stimulus classes. We also observed effects in the cerebellum for the "single, regular change" and "multiple, irregular change" stimulus classes.

Effects related to stimulus spectral and temporal variations were identified by comparing, respectively, the multiple to the single stimulus classes (independent of changes over time; Figure 5B,
GREEN) and the changing to the unchanging stimulus classes (independent of the number of frequency components; Figure 5B, BLUE). The coordinates of the effects related to increasing auditory complexity are reported in Table 5. Overlapping sensitivity to spectral and temporal effects was observed in the lateral portion of HG. Increasing numbers of frequency components were associated with greater effects in posterior and lateral non-primary auditory fields, specifically bilateral posterolateral STG and PT. Modulatory effects were also seen in inferior frontal gyrus (BA 45, 47). In contrast, the effects related to temporal modulations compared to their absence were observed in HG, anterior STG, anterior STS, inferior frontal cortex (BA 46, 47), and right cerebellum (lobule IV).

\section{DISCUSSION}

\section{SUMMARY OF FINDINGS}

In a quantitative meta-analysis of 58 neuroimaging studies, we examined the functional specialization of human auditory cortex using two different strategies for classifying sounds. The first strategy employed typical categories, such as pure tones, noise, music, and vocal sounds. The second strategy categorized sounds according to their acoustical (spectral and temporal) complexity.

Activation Likelihood Estimation maps computed for each typical sound category included simple (pure tones) and complex (noise, voices, and music) sounds. This analysis gave results consistent with models describing hierarchical functional organization of the human auditory cortex, with simple sounds eliciting activity in the primary auditory cortex and complex sound processing engaging additional activity in non-primary fields. We observed an expected leftward hemispheric specialization for intelligible speech, while right-hemisphere specialization for music was less evident. Additionally, the comparison of intelligible speech to complex nonspeech stimuli yielded bilateral effects along the STG and STS, with higher sensitivity to speech intelligibility in the left anterior STG.

Examining an alternative classification based on stimulus variation along spectral and temporal dimensions, we observed a withinhemisphere functional segregation, with spectral effects strongest in posterior STG and temporal modulations strongest in anterior 


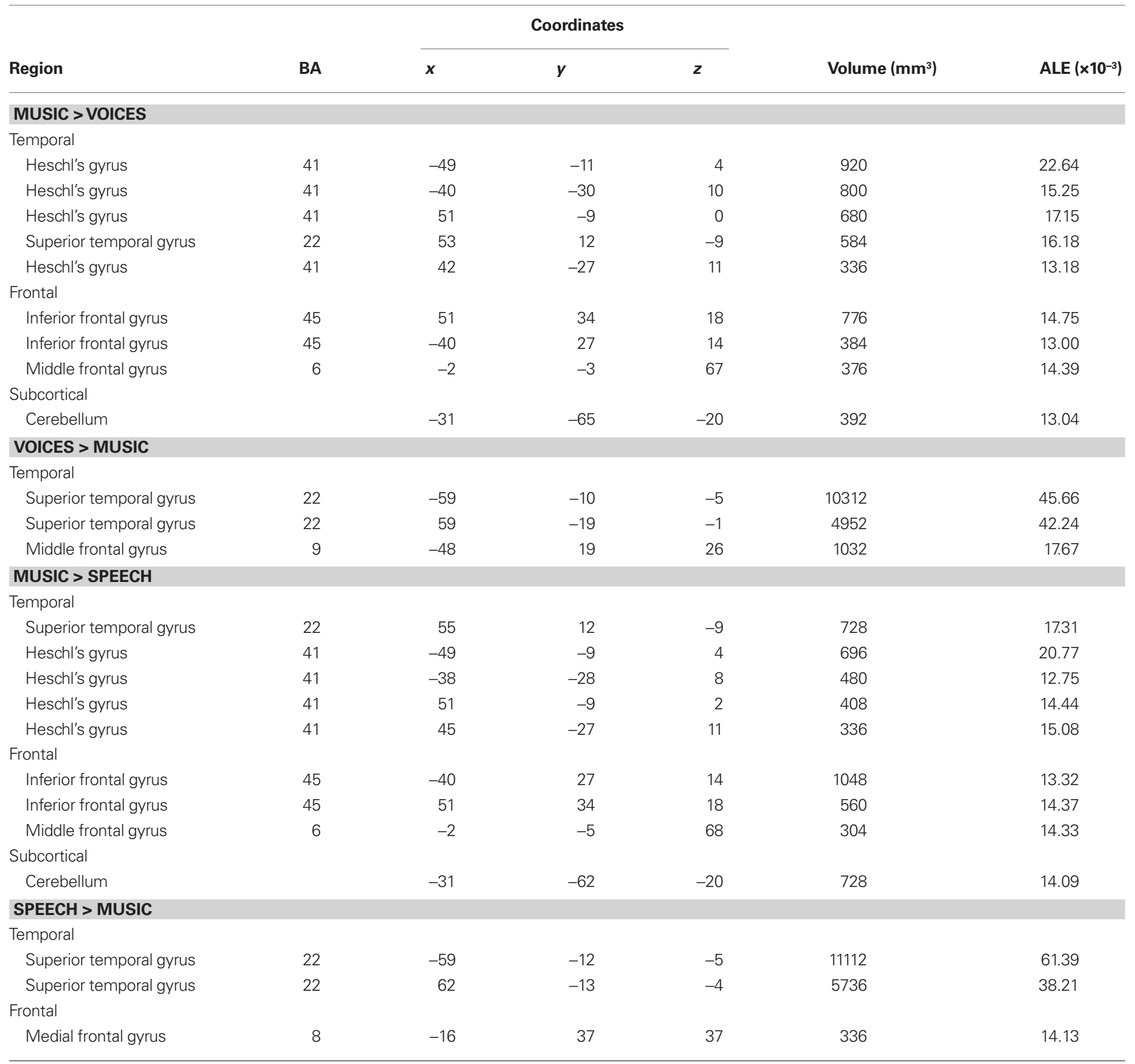

MNI coordinates of the locations of significant ALE maxima resulting from the comparison between speech and music $(p<0.01, k=250$ voxels).

temporal STG. We suggest that acoustic complexity might represent a valid alternative classificatory scheme to describe a novel withinhemisphere dichotomy regarding the functional organization for auditory processing in temporal cortex.

\section{HIERARCHICALLY AND HEMISPHERICALLY SPECIALIZED ARCHITECTURES FOR AUDITORY PROCESSING}

Originally elaborated on the basis of non-human primate studies, the hierarchical functional organization scheme in auditory cortex incorporates three levels of processing: core (primary area), belt and parabelt (non-primary areas). Simple sound processing is thought to solely recruit the core region whereas complex sounds are believed to elicit activity in core, belt, and parabelt areas. While belt region responses are thought to be sensitive to acoustic feature variations, the parabelt, and more anterior temporal regions, show greater sensitivity to complex sounds such as vocalizations (Rauschecker, 1998; Hackett, 2008; Rauschecker and Scott, 2009; Woods and Alain, 2009). Our quantitative meta-analysis using typical sound classes confirmed that hierarchical processing is a feature that can adequately describe human auditory cortical organization.

Using an ALE analysis of pure tone processing to investigate the correspondence between the core region and activity related to simple sound processing, we observed ALE extrema values bilaterally in medial HG, the putative location of primary auditory 
Table 4 | Functional specialization for speech sounds.

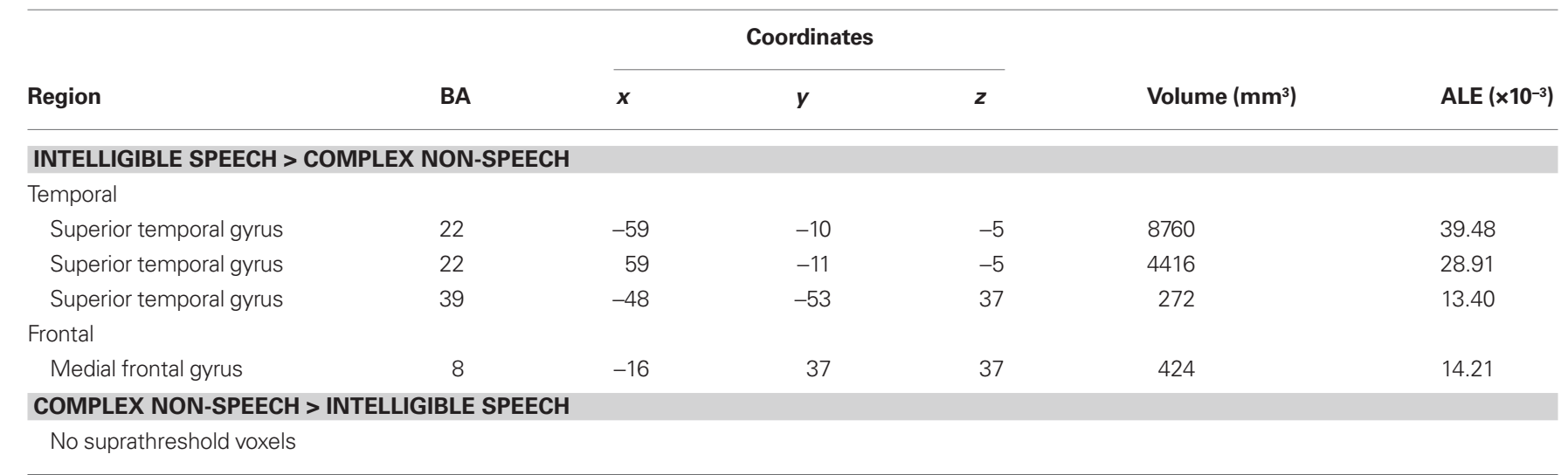

MNI coordinates of the locations of significant ALE maxima resulting from the comparison between speech and complex non-speech contrasts $(p<0.01, k=250$ voxels).

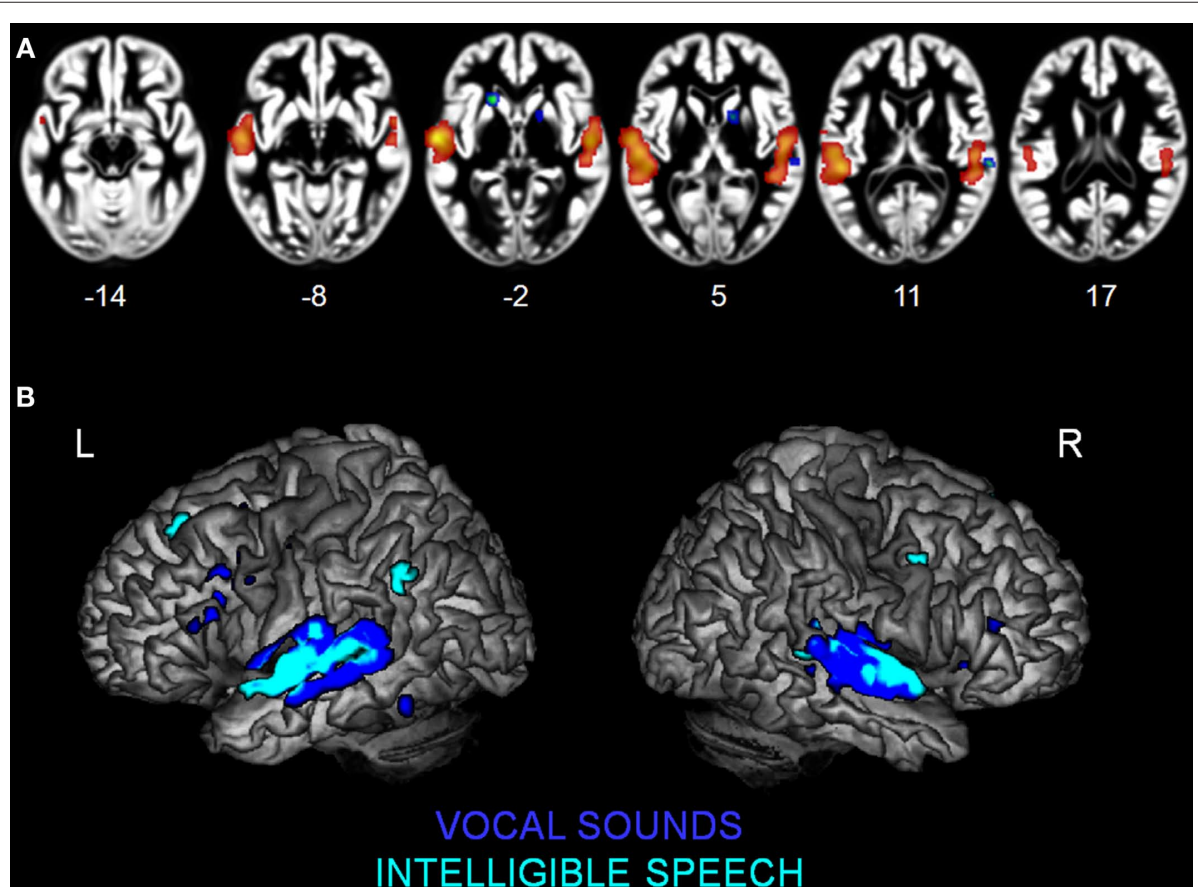

FIGURE 3 | Activation Likelihood Estimation maps showing clusters of activity related to $(A)$ intelligible speech > complex non-speech sounds (RED-YELLOW) and to intelligible speech < complex non-speech (BLUEGREEN). Axial images are shown using the neurological convention with
MNI z-coordinate labels. (B) Rendering of ALE maps related to vocal sound category (dark blue) and to speech intelligibility (pale blue). The maps are superimposed on anatomical templates in MNI space $\left(p_{\mathrm{FDR}}<0.01\right)$ cortex. This finding is consistent with previous electrophysiological (Hackett et al., 2001), cytoarchitectural (Sweet et al., 2005), and functional imaging (Lauter et al., 1985; Bilecen et al., 1998; Lockwood et al., 1999; Wessinger et al., 2001) studies of the human auditory cortex that have localized the core region to medial HG. Our findings confirm the existence of functional specialization for simple sound processing in the human core homolog. Consequently, the statistical probability maps obtained here could serve to functionally define primary auditory cortex in a region of interest analysis of functional neuroimaging data.
In contrast, we expected ALE analyses of the complex sound categories to show activity in all three levels of the processing hierarchy. We observed overlapping activity among the complex sound maps in medial HG (core) as well as stronger activity related to complex sound processing in regions surrounding medial HG, corresponding to the areas described as the auditory belt/parabelt in primates (Rauschecker, 1998; Kaas and Hackett, 2000; Rauschecker and Scott, 2009; Recanzone and Cohen, 2010) and humans (Rivier and Clarke, 1997; Wallace et al., 2002; Sweet et al., 2005). The fact that the complex sound maps showed effects in medial HG activity 
Table 5 | Complexity classification.

\section{Coordinates}

\begin{tabular}{|c|c|c|c|c|c|c|}
\hline \multirow[b]{2}{*}{ Region } & \multirow[b]{2}{*}{ BA } & & \multirow{2}{*}{ Volume $\left(\mathrm{mm}^{3}\right)$} & \multirow{2}{*}{$\operatorname{ALE}\left(\times 10^{-3}\right)$} \\
\hline & & $x$ & $y$ & $z$ & & \\
\hline \multicolumn{7}{|l|}{ Single unchanging } \\
\hline Heschl's gyrus & 41 & 53 & -17 & 1 & 3880 & 26.00 \\
\hline Heschl's gyrus & 41 & -51 & -18 & 0 & 2488 & 16.85 \\
\hline \multicolumn{7}{|l|}{ Single regular change } \\
\hline Superior temporal gyrus & 22 & -57 & -15 & 5 & 4080 & 24.31 \\
\hline \multicolumn{7}{|l|}{ Sub cortical } \\
\hline Cerebellum & & 23 & -62 & -21 & 352 & 7.98 \\
\hline \multicolumn{7}{|l|}{ Multiple unchanging } \\
\hline \multicolumn{7}{|l|}{ Temporal } \\
\hline Superior frontal gyrus & 6 & 13 & 14 & 57 & 448 & 11.36 \\
\hline Inferior frontal gyrus & 9 & 45 & 15 & 20 & 408 & 10.28 \\
\hline \multicolumn{7}{|l|}{ Multiple regular change } \\
\hline \multicolumn{7}{|l|}{ Temporal } \\
\hline Superior temporal gyrus & 42 & 66 & -21 & 5 & 6256 & 22.56 \\
\hline Superior temporal gyrus & 42 & -59 & -21 & 12 & 6096 & 21.90 \\
\hline \multicolumn{7}{|l|}{ Frontal } \\
\hline Inferior frontal gyrus & 46 & 62 & 35 & 7 & 848 & 15.86 \\
\hline Inferior frontal gyrus & 47 & -42 & 27 & -4 & 688 & 12.63 \\
\hline \multicolumn{7}{|l|}{ Multiple irregular change } \\
\hline Temporal & & & & & & \\
\hline Superior temporal gyrus & 22 & -59 & -23 & 10 & 8352 & 33.26 \\
\hline Superior temporal gyrus & 22 & 68 & -21 & 5 & 8256 & 42.55 \\
\hline Frontal & & & & & & \\
\hline Inferior frontal gyrus & 46 & 62 & 35 & 7 & 448 & 15.86 \\
\hline Inferior frontal gyrus & 47 & -42 & 27 & -4 & 384 & 13.50 \\
\hline Subcortical & & & & & & \\
\hline Cerebellum & & 29 & -56 & -26 & 872 & 14.98 \\
\hline Thalamus & & 14 & -19 & 2 & 352 & 12.62 \\
\hline Changing > unchanging & & & & & & \\
\hline Temporal & & & & & & \\
\hline Superior temporal gyrus & 22 & 59 & -11 & 2 & 8808 & 29.96 \\
\hline Superior temporal gyrus & 22 & -57 & -9 & -3 & 5552 & 33.22 \\
\hline Superior temporal sulcus & 22 & -64 & -34 & 7 & 336 & 10.54 \\
\hline Frontal & & & & & & \\
\hline Inferior frontal gyrus & 46 & 62 & 35 & 7 & 440 & 15.85 \\
\hline Inferior frontal gyrus & 47 & -42 & 27 & -4 & 360 & 13.50 \\
\hline Subcortical & & & & & & \\
\hline Cerebellum & & 23 & -58 & -24 & 1072 & 17.22 \\
\hline
\end{tabular}

MNI coordinates of the locations of significant ALE maxima for each level of acoustic complexity and comparison between levels $(p<0.01, k=250$ voxels). 


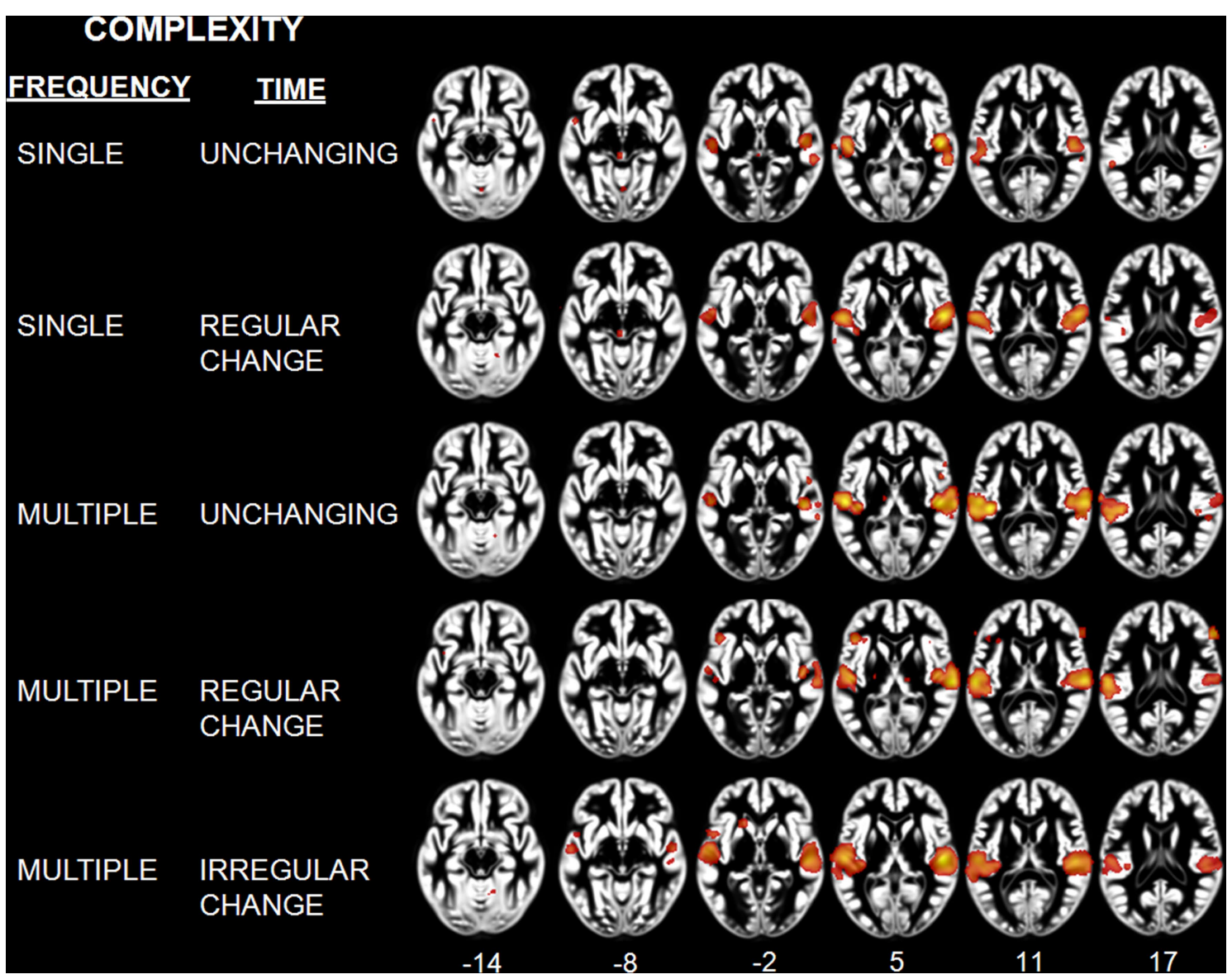

FIGURE 4 | Activation Likelihood Estimation maps showing effects related to each level of complexity: Single unchanging, single regular change, multiple unchanging, multiple regular change, and multiple irregular change. Maps are superimposed on an anatomical template in MNI space. Axial images are shown using the neurological convention with $\mathrm{MNI} z$-coordinate labels $\left(p_{\mathrm{FDR}}<0.01\right)$.

supports the notion that primary auditory regions participate in the early stages of processing upon which further complex processing is built.

Outside primary auditory cortex, noise elicited activity in posterior temporal non-primary fields such as PT. The spatial pattern was similar to that observed in relation to broadband noise, stimuli that have been used to demonstrate the hierarchical organization of human auditory cortex (Wessinger et al., 2001). The PT is generally believed to be involved in complex sound analysis and participate in both language and other cognitive functions (Griffiths and Warren, 2002).

For music, in addition to primary auditory cortex activity, we observed activity in non-primary auditory fields along the STG bilaterally. This result is consistent with the idea that simple extraction and low-level ordering of pitch information involves processes within primary auditory fields, while higher-level processing for tone patterns and melodies involve non-primary auditory fields and association cortex (Zatorre et al., 2002). Moreover, non-primary regions in anterior and posterior STG are thought to process melody pitch intervals (Patterson et al., 2002; Tramo et al., 2002; Warren and Griffiths, 2003). Music also elicited strong inferior frontal cortex activity, a region thought to process musical syntax (Zatorre et al., 1994; Maess et al., 2001; Koelsch et al., 2002).
For vocal sounds, we observed strong bilateral temporal lobe activity in anterior and posterior parts of dorsal STG and the STS, findings consistent with earlier studies (Binder et al., 1994; Belin, 2006). STG activity in response to vocal sounds has previously been interpreted as a neural correlate of the rapid and efficient processing of the complex frequency patterns and temporal variations characterizing speech. The human STG is thought to subserve complex auditory processing, such as vocalizations, as is the STG in non-human primates (Rauschecker et al., 1995). Belin and colleagues (Belin et al., 2000, 2002; Fecteau et al., 2004) reported cortical responses to voices along the upper bank of the middle and anterior STS. The anterior STS is selectively responsive to human vocal sounds (Belin et al., 2000). Response specificity to vocal sounds and their rich identity and affective information content is of crucial importance, as it reflects a set of high-level auditory cognitive abilities that can be directly compared between human and non-human primates. The regions described as "Temporal Voice Areas" in humans (Belin et al., 2000) are thought to be functionally homologous to the temporal voice regions recently described in macaques (Petkov et al., 2008). Our meta-analysis using typical sound categories demonstrates that, in humans, simple sound processing elicits activity limited to the core area while complex sounds elicit effects in all three cortical processing levels. 


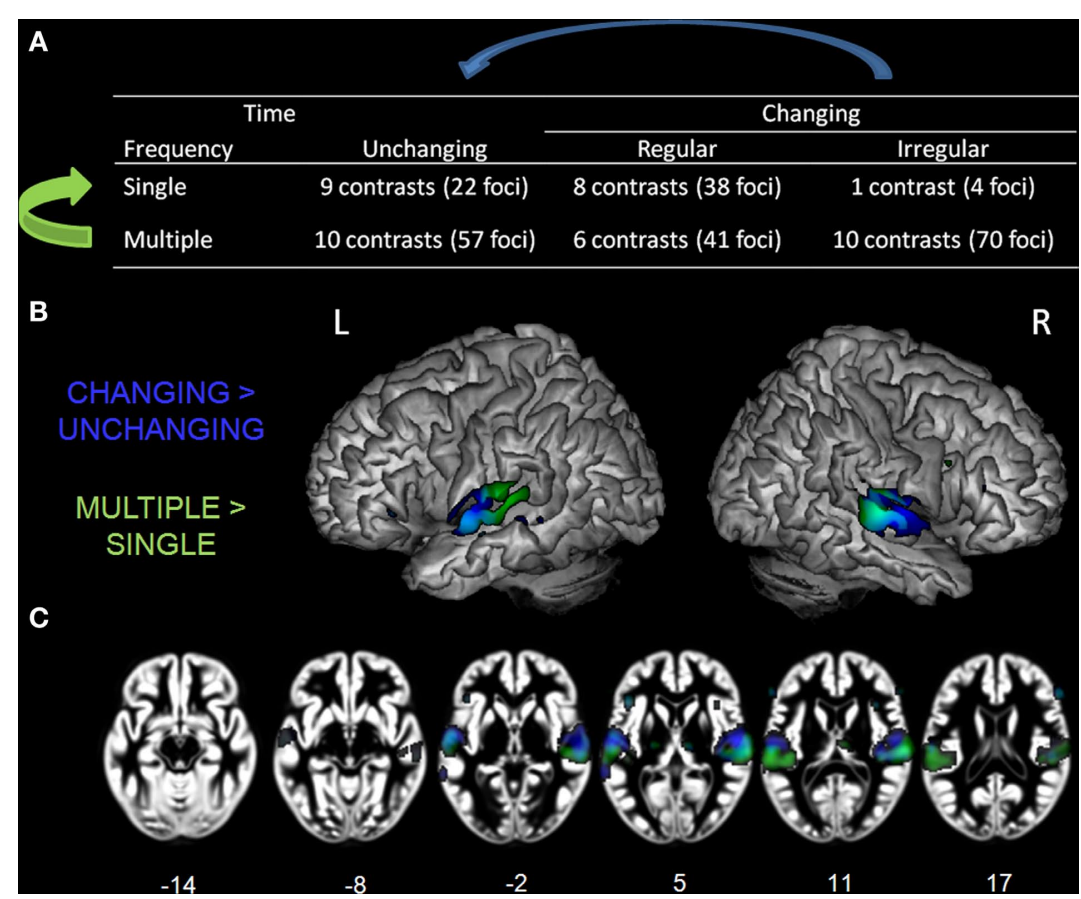

FIGURE 5 | Table of complexity levels and corresponding number of contrasts. (A) Rendering (B) and axial overlay (C) of the ALE maps reflecting the effects related to frequency (GREEN) and time (BLUE) complexity axis. Maps are superimposed on an anatomical template in MNI space. Axial images are shown using the neurological convention with MNI $z$-coordinate labels $\left(p_{\mathrm{FDR}}<0.01\right)$.

In addition to the hierarchical organization of auditory cortex, we expected hemispheric asymmetries for music and speech, and observed the expected left lateralization of auditory cortex responses to vocal sounds and intelligible speech. For vocal sounds, lateralization effects were observed only as a larger volume of auditory activity on the left while, for the speech sounds, the left auditory cortical responses were larger and stronger (higher ALE values) than the right-hemisphere responses. Greater lateralization effects for intelligible speech is in agreement with previous independent imaging studies, not included in this meta-analysis, reporting that intelligible speech sounds elicit strong activity in left STG and STS (e.g., Scott et al., 2000; Liebenthal et al., 2005; Obleser et al., 2007). Conversely, we did not see the expected right response lateralization related to music. Possibly, the small number of experiments included in the music category limited the power of this analysis and could have prevented us from observing the expected rightward auditory response. ALE maps derived from small samples are more sensitive to between-study cohort heterogeneity that could limit the detection of hemispheric effects. It is also possible that the right hemisphere is sensitive to particular features of musical stimuli such as fine pitch changes (Hyde et al., 2008) or to specific task demands like contextual pitch judgment (i.e., contextual pitch judgment Warrier and Zatorre, 2004) which were not present in our sample.

\section{RESPONSE SPECIFICITY TO SPEECH INTELLIGIBILITY}

Within the general category of vocal sounds, a human-specific category of intelligible speech can be further distinguished. Response specificity to speech intelligibility is an important part of understanding the human-specific neural network underlying speech comprehension, and ultimately human language and communication.

In order to identify speech-specific processes, we directly compared intelligible speech to complex non-speech contrasts that included unintelligible spectro-temporally complex sounds. This comparison yielded stronger speech-related activity in lateral non-primary superior temporal regions, specifically in posterior STG, and anterior and middle STS. The effects were stronger and larger in the left hemisphere. Similar effects have been reported in independent studies examining specialization for processing speech sound that did not fulfill our inclusion criteria for this analysis (Scott et al., 2000; Davis and Johnsrude, 2003; Narain et al., 2003; Thierry et al., 2003; Liebenthal et al., 2005). Consistent with the present finding, these previous reports emphasized that speech-specific STS responses are more left-lateralized.

Beyond the auditory cortex, we observed activity in left inferior frontal and prefrontal cortex. These findings support an expanded hierarchical model of speech processing that originates in primary auditory areas and extends to non-auditory regions, mainly within frontal cortex, in a range of motor, premotor, and prefrontal regions (Davis and Johnsrude, 2007; Hickok and Poeppel, 2007; Rauschecker and Scott, 2009). In non-human primates, based on reports of high level of connection between the auditory and frontal cortex, it has been proposed that frontal regions responsive to auditory material should be considered as part of the auditory system (Hackett et al., 1999; Kaas et al., 1999; Romanski et al., 1999). 


\section{FUNCTIONAL SPECIALIZATION OF THE AUDITORY CORTEX RESPONSE: ACOUSTIC COMPLEXITY EFFECTS}

As an alternative to the classical division of auditory stimuli into typical categories like pure tones, noise, voices, and music, we explored how acoustic variations along the temporal and spectral dimensions were represented at the cortical level. This approach for defining auditory material is an efficient and comprehensive characterization of sounds that can be considered as a complement to the more typically studied categorical effects. Possibly, certain aspects of human auditory processes might be better characterized in terms of their capacity to analyze acoustic features rather than having differential sensitivity to typical sound categories. In a meta-analysis Rivier and Clarke (1997) found no clear functional specialization in non-primary auditory fields for a range of complex sound categories, showing that processing sounds of different categories such as noise, words, and music, elicited activity in multiple non-primary fields around HG with no emergence of a specific organizational pattern. Similarly, Griffiths and Warren (2002) reported that activity within the PT, an auditory association region, is not spatially organized according to sound categories such as music, speech or, environmental sounds.

By classifying sounds according to their variations in time and frequency, we isolated different levels of auditory complexity, suggesting a within-hemisphere functional segregation with anterior STG and STS more sensitive to changes in the temporal domain and posterior regions (PT and posterolateral STG) more sensitive to changes in along the spectral dimension. Interestingly, a partial overlap was observed between regions sensitive to temporal and spectral changes in lateral HG, suggesting great sensitivity to variations in acoustic properties within this region, consistent with a recent report of strongest sensitivity to stimulus acoustic features within HG (Okada et al., 2010).

Our observation of differential sensitivity to temporal and spectral features can be interpreted in the light of previous findings. First, in the animal literature, a within-hemisphere model of spectral and temporal processing in the auditory cortex has been proposed (Bendor and Wang, 2008). This scheme suggests two streams of processing originating from primary auditory cortex; an anterior pathway sensitive to temporal changes and a lateral pathway responsive to spectral changes. More precise temporal coding is seen as one progresses from primary to anterior auditory regions in primates (Bendor and Wang, 2007) and greater sensitivity to temporal modulations in anterior non-primary auditory fields is also observed in cats (Tian and Rauschecker, 1994). Possibly, a longer integration window in anterior auditory fields could underlie complex temporal processing (Bendor and Wang, 2008). As regards spectral processing, increasing sensitivity to broadband spectrum noise compared to single tones has been observed in lateral and posterior auditory fields in non-human primates (Rauschecker and Tian, 2004; Petkov et al., 2006). Furthermore, given that the neurons within these regions show strong tuning to bandwidth and frequency, some have suggested their involvement in the early stages of spectral analysis of complex sounds (Rauschecker and Tian, 2004). In our study, sensitivity to temporal changes was observed in anterior temporal regions, while, in response to changes along the spectral dimension, we mainly observed response selectivity in posterolateral auditory fields. Our results therefore seem to be consistent with previous animal studies.

Second, cortical response specificity to spectral and temporal processing has also been studies in humans. Whereas some studies reported no clear functional segregation between responses to spectral and temporal cues (Hall et al., 2002) or observed neuronal populations tuned to specific combinations of spectrotemporal cues (Schönwiesner and Zatorre, 2009), other studies found the sorts of specific sensitivity to spectral vs. temporal features in human auditory cortex we observed in our meta-analysis. For instance, lateral HG and anterolateral PT activity have been reported in association with fine spectral structure analysis (Warren et al., 2005) and change detection of complex harmonic tones involved the posterior STG and lateral PT (Schönwiesner et al., 2007). Additionally, recent studies examining effective connectivity effects among auditory regions reported that spectral envelope analysis follows a serial pathway from $\mathrm{HG}$ to PT and then to the STS (Griffiths et al., 2007; Kumar et al., 2007). Conversely for temporal complexity effects, a stream of processing from primary auditory cortex to anterior STG has been observed for auditory pattern analysis such as dynamic pitch variation (Griffiths et al., 1998). Similarly, significant effects of temporal modulation have been reported in anterior non-primary auditory fields (Hall et al., 2000). Some studies therefore report patterns of activity consistent with the current findings, albeit separately for spectral and temporal features.

A more frequently observed feature of spectral vs. temporal processing is between-hemisphere functional specialization. Most studies observed slight but significant lateralization effects with a left-lateralized response to temporal information and rightlateralized activity to spectral information (Zatorre and Belin, 2001; Schönwiesner et al., 2005; Jamison et al., 2006; Obleser et al., 2008). In the current study, lateralization effects were not seen with regard to complexity. However, at higher processing levels, leftward lateralization for speech was observed. Others studies failing to demonstrate the expected lateralization proposed that early stages of processing involve bilateral auditory cortex and that higher cognitive functions, such as speech processing, also rely on these regions but involve more extensive regions in the dominant hemisphere (Langers et al., 2003). Alternatively, Tervaniemi and Hugdahl (2003) reviewed studies showing that response lateralization within the auditory cortex is dependent on sound structure as well as the acoustic background they are presented in. For instance, reduced or absent hemispheric specialization for speech sounds has been reported when the amount of formant structure is not sufficient to establish phoneme categorization (Rinne et al., 1999) or when sounds are presented in noise (Shtyrov et al., 1998). Stimulus heterogeneity among the different experiments included in our meta-analysis could explain why we did not observe asymmetrical hemispheric effects.

To summarize, our meta-analysis demonstrates a clear withinhemisphere functional segregation related to spectral and temporal processing in human auditory cortex, consistent with the known organization of non-human primate auditory system. That such clear spectral vs. temporal complexity gradients are observed (Figure 5), while very few of the included studies have explicitly addressed this issue, illustrates the power of the meta-analysis 
approach for human neuroimaging studies. Based on the observed regional functional segregation, we argue that acoustic complexity could well represent a relevant stimulus dimension upon which to identify response segregation within the auditory system. Complexity and categorical effects could therefore be considered as two complementary approaches to more fully characterizing the underlying nature of auditory regional functional specialization.

\section{REFERENCES}

Belin, P. (2006). Voice processing in human and non-human primates. Philos. Trans. R. Soc. Lond., B, Biol. Sci. 361, 2091-2107.

Belin, P., Zatorre, R. J., and Ahad, P. (2002). Human temporal-lobe response to vocal sounds. Brain Res. Cogn. Brain Res. 13, 17-26.

Belin, P., Zatorre, R. J., Hoge, R., Evans, A. C., and Pike, B. (1999). Eventrelated fMRI of the auditory cortex. Neuroimage 10, 417-429.

Belin, P., Zatorre, R. J., Lafaille, P., Ahad, P., and Pike, B. (2000). Voice-selective areas in human auditory cortex. Nature 403, 309-312.

Belin, P., Zilbovicius, M., Crozier, S., Thivard, L, Fontaine, A., Masure, M.-C., and Samson, Y. (1998). Lateralization of speech and auditory temporal processing. J. Cogn. Neurosci. 10, 4, 536-540.

Bendor, D., and Wang, X. (2007). Differential neural coding of acoustic flutter within primate auditory cortex. Nat. Neurosci. 10, 763-771.

Bendor, D., and Wang, X. (2008). Neural response properties of primary, rostral, and rostrotemporal core fields in the auditory cortex of marmoset monkeys. J. Neurophysiol. 100, 888-906.

Benson, R. R., Richardson, M., Whalen, D. H., and Lai, S. (2006). Phonetic processing areas revealed by sinewave speech and acoustically similar nonspeech. Neuroimage 31, 342-353.

Benson, R. R., Whalen, D. H., Richardson, M., Swainson, B., Clark, V. P., Lai, S., and Liberman, A. M. (2001). Parametric dissociating speech and nonspeech perception in the brain using fMRI. Brain Lang. 78, 364-396.

Bilecen, D., Scheffler, K., Schmid, N., Tschopp, K., and Seelig, J. (1998). Tonotopic organization of the human auditory cortex as detected by BOLDFMRI. Hear. Res. 126, 19-27.

Binder, J. R., Frost, J. A., Hammeke, T. A., Bellgowan, P. S. F., Springer, J. A., Kaufman, J. N., and Possing, E. T. (2000). Human temporal lobe activation by speech and nonspeech sounds. Cereb. Cortex 10, 512-528.

Binder, J. R., Frost, J. A., Hammeke, T. A., Rao, S. M., and Cox, R. W. (1996). Function of the left planum temporale in auditory and linguistic processing. Brain 119(Pt 4), 1239-1247.

Binder, J. R., Rao, S. M., Hammeke, T. A., Yetkin, F. Z., Jesmanowicz, A., Bandettini,P.A., Wong,E.C., Estkowski, L. D., Goldstein, M.D., and Haughton, V. M. (1994). Functional magnetic resonance imaging of human auditory cortex. Ann. Neurol. 35, 662-672.

Binder, J. R., Swanson, S. J., Hammeke, T. A., and Sabsevitz, D. S. (2008). A comparison of five fMRI protocols for mapping speech comprehension systems. Epilepsia 49, 1980-1997.

Blood, A. J., Zatorre, R. J., Bermudez, P., and Evans, A. C. (1999). Emotional responses to pleasant and unpleasant music correlate with activity in paralimbic brain regions. Nat. Neurosci. 2, 382-387.

Brown, S., Martinez, M. J., and Parsons, L. M. (2004). Passive music listening spontaneously engages limbic and paralimbic systems. Neuroreport 15 , 2033-2037.

Burton, M. W., and Small, S. L. (2006). Functional neuroanatomy of segmenting speech and nonspeech. Cortex 42 , 644-651.

Burton, M., W.; Small, S.L., and Blumstein, S. E. (2000). The role of segmentation in phonological processing: an fMRI investigation. J. Cogn. Neurosci. 12, 679-690.

Celsis, P., Boulanouar, K., Doyon, B., Ranjeva, J. P., Berry, I., Nespoulous, J. L., and Chollet, F. (1999). Differential fMRI responses in the left posterior superior temporal gyrus and left supramarginal gyrus to habituation and change detection in syllables and tones. Neuroimage 9, 135-144.

Chen, J. L., Penhune, V. B., and Zatorre, R J. (2008). Listening to musical rhythms recruits motor regions of the brain. Cereb. Cortex 18, 2844-2854.

Chubb, C., and Sperling, G. (1988). Drift-balanced random stimuli: a general basis for studying non-Fourier motion perception. J. Opt. Soc. Am. A 5, 1986-2007.

Dalla Barba, G., Parlato, V., Jobert, A., Samson, Y., and Pappata, S. (1998). Cortical networks implicated in semantic and episodic memory: common or unique? Cortex 34, 547-561.

Davis, M. H., and Johnsrude, I. S. (2003). Hierarchical processing in spoken

\section{ACKNOWLEDGMENTS}

We would like to thank Dr. Laurent Mottron and Dr. Valter Ciocca for providing comments on the manuscript and suggestions regarding the stimulus categorizations. This work was supported by Canadian Institutes for Health Research (grant MOP-84243) as well as a doctoral award from Natural Sciences and Engineering Research Council of Canada to Fabienne Samson.

language comprehension. J. Neurosci. 23, 3423-3431.

Davis, M. H., and Johnsrude, I. S. (2007). Hearing speech sounds: top-down influences on the interface between audition and speech perception. Hear. Res. 229, 132-147.

Dehaene-Lambertz, G., Pallier, C., Serniclaes, W., Sprenger-Charolles, L., Jobert, A., and Dehaene, S. (2005) Neural correlates of switching from auditory to speech perception. Neuroimage 24, 21-33.

Démonet, J.-F., Chollet, F., Ramsay, S., Cardebat, D., Nespoulous, J., Wise, R., Rascol, A., and Frackowiak, R. (1992). The anatomy of phonological and semantic processing in normal subjects. Brain 115, 1753-1768.

De Nil, L. F., Beal, D. S., Lafaille, S. J., Kroll, R. M., Crawley, A. P., and Gracco, V.L. (2008). The effects of simulated stuttering and prolonged speech on the neural activation patterns of stuttering and nonstuttering adults. Brain Lang. $107,114-123$.

Dufor, O., Serniclaes, W., SprengerCharolles, L., and Démonet, J. F. (2007). Top-down processes during auditory phoneme categorization in dyslexia: a PET study. Neuroimage 34, 1692-1707.

Engelien, A., Tüscher, O., Hermans, W., Isenberg, N., Eidelberg, D., Frith, C. Stern, E., and Silbersweig, D. (2006). Functional neuroanatomy of nonverbal semantic sound processing in humans. J. Neural Transm. 113 , 599-608.

Fecteau, S., Armony, J. L., Joanette, Y. and Belin, P. (2004). Is voice processing species-specific in human auditory cortex? An fMRI study. Neuroimage 23 840-848.

Fernandez-Espejo, D., Junque, C., Vendrell, P., Bernabeu, M., Roig, T., Bargallo, N., and Mercader, J. M. (2008). Cerebral response to speech in vegetative and minimally conscious states after traumatic brain injury. Brain Inj. 22, 882-890.

Fox, P. T., Parsons, L. M., and Lancaster, J. L. (1998). Beyond the single study: function/location metanalysis in cognitive neuroimaging. Curr. Opin. Neurobiol. 8, 178-187.

Gaab, N., Gabrieli, J. D. E., and Glover, G. H. (2007a). Assessing the influence of scanner background noise on auditory processing. I. An fMRI study comparing three experimental designs with varying degrees of scanner noise. Hum. Brain Mapp. 28, 703-720.

Gaab, N., Gabrieli, J. D. E., and Glover, G. H. (2007b). Assessing the influence of scanner background noise on auditory processing. II. An fMRI study comparing auditory processing in the absence and presence of recorded scanner noise using a sparse design. Hum. Brain Mapp. 28, 721-732.

Giraud, A. L., Kell., C., Thierfelder, C., Sterzer,P., Russ, M.O.,Preibisch, C., and Kleinschmidt,A. (2004). Contributions of sensory input, auditory search and verbal comprehension to cortical activity during speech processing. Cereb. Cortex 14, 247-255.

Griffiths, T. D., and Warren, J. D. (2002). The planum temporale as a computational hub. Trends Neurosci. 25, 348-353.

Griffiths, T. D., and Warren, J. D. (2004). What is an auditory object? Nat. Rev. Neurosci. 5, 887-892.

Griffiths, T. D., Buchel, C., Frackowiak, R. S., and Patterson, R. D. (1998). Analysis of temporal structure in sound by the human brain. Nat. Neurosci. 1, 422-427.

Griffiths, T. D., Kumar, S., Warren, J. D., Stewart, L., Stephan, K. E., and Friston, K. J. (2007).Approaches to the cortical analysis of auditory objects. Hear. Res. 229, 46-53.

Hackett, T.A. (2008). Anatomical organization of the auditory cortex. J. Am. Acad. Audiol. 19, 774-779.

Hackett, T. A., Preuss, T. M., and Kaas, J. H. (2001).Architectonicidentification of the core region in auditory cortex of macaques, chimpanzees, and humans. J. Comp. Neurol. 441, 197-222.

Hackett, T. A., Stepniewska, I., and Kaas, J. H. (1999). Prefrontal connections of the parabelt auditory cortex in macaque monkeys. Brain Res. 817, 45-58.

Hall, D. A., Haggard, M. P., Akeroyd, M. A., Summerfield, A. Q., Palmer, A. R., Elliott, M. R., and Bowtell, R. W. (2000). Modulation and task effects in auditory processing measured using fMRI. Hum. Brain Mapp. 10, 107-119.

Hall, D. A., Johnsrude, I. S., Haggard, M. P., Palmer, A. R., Akeroyd, M. A., and 
Summerfield, A. Q. (2002). Spectral and temporal processing in human auditory cortex. Cereb. Cortex 12, 140-149.

Hart, H. C., Palmer, A. R., and Hall, D. A. (2003). Amplitude and frequency modulated stimuli activate common regions of human auditory cortex. Cereb. Cortex 13, 773-781.

Hart, H. C., Palmer, A. R., and Hall, D. A. (2004). Different areas of human nonprimary auditory cortex are activated by sounds with spatial and nonspatial properties. Hum. Brain Mapp. 21, 178-190.

Hertrich, I., Dietrich, S., and Ackermann, H. (2010). Cross-modal interactions during perception of audiovisual speech and nonspeech signals: an fMRI study. J. Cogn. Neurosci. 23, 221-237.

Hickok, G., and Poeppel, D. (2007). The cortical organization of speech processing. Nat. Rev. Neurosci. 8, 393-402.

Hugdahl, K., Thomsen, T., Ersland, L., Rimol, L.M., and Niemi, J. (2003). The effects of attention on speech perception: an fMRI study. Brain Lang. 85, 37-48.

Hwang, J.H., Li, C. W., Wu, C. W., Chen, J. H., and Liu, T. C. (2007). Aging effects on the activation of the auditory cortex during binaural speech listening in white noise: an fMRI study. Audiol. Neurootol. 12, 285-294.

Hyde, K. L., Peretz, I., and Zatorre, R. J. (2008). Evidence for the role of the right auditory cortex in fine pitch resolution. Neuropsychologia 46, 632-639.

Jamison, H. L., Watkins, K. E., Bishop, D. V., and Matthews, P. M. (2006). Hemispheric specialization for processing auditory nonspeech stimuli. Cereb. Cortex 16, 1266-1275.

Jäncke, L., Shah, N. J., Posse, S., GrosseRyuken, M., and Müller-Gärtner, H.-W. (1998). Intensity coding of auditory stimuli: an fMRI study. Neuropsychologia 36, 875-883.

Kaas, J. H., and Hackett, T. A. (2000). Subdivisions of auditory cortex and processing streams in primates. Proc. Natl. Acad. Sci. U.S.A. 97, 11793-11799.

Kaas, J. H., Hackett, T. A., and Tramo, M. J. (1999). Auditory processing in primate cerebral cortex. Curr. Opin. Neurobiol. 9, 164-170.

Koelsch, S., Gunter, T. C., v Cramon, D. Y., Zysset, S., Lohmann, G., and Friederici, A. D. (2002). Bach speaks: a cortical "language-network" serves the processing of music. Neuroimage $17,956-966$.

Kriegstein, K.V., and Giraud, A. L. (2004). Distinct functional substrates along the right superior temporal sulcus for the processing of voices. Neuroimage $22,948-955$.

Kumar, S., Stephan, K. E., Warren, J. D., Friston, K. J., and Griffiths, T. D. (2007). Hierarchical processing of auditory objects in humans. PLoS Comput. Biol. 3, e100. doi: 10.1371/ journal.pcbi.0030100

Laird, A. R., Fox, P. M., Price, C. J., Glahn, D. C., Uecker, A. M., Lancaster, J. L., Turkeltaub, P. E., Kochunov, P., and Fox, P. T. (2005). ALE meta-analysis: controlling the false discovery rate and performing statistical contrasts. Hum. Brain Mapp. 25, 155-164.

Lancaster, J. L., Tordesillas-Gutierrez, D., Martinez, M., Salinas, F., Evans, A., Zilles, K., Mazziotta, J. C., and Fox, P. T. (2007). Bias between MNI and Talairach coordinates analyzed using the ICBM-152 brain template. Hum. Brain Mapp. 28, 1194-1205.

Langers, D. R., Backes, W. H., and van Dijk, P. (2003). Spectrotemporal features of the auditory cortex: the activation in response to dynamic ripples. Neuroimage 20, 265-275.

Larsson, J., Landy, M. S., and Heeger, D. J. (2006). Orientation-selective adaptation to first- and second-order patterns in human visual cortex. $J$. Neurophysiol. 95, 862-881.

Lauter, J. L., Herscovitch, P., Formby, C., and Raichle, M. E. (1985). Tonotopic organization in human auditory cortex revealed by positron emission tomography. Hear. Res. 20, 199-205.

Leaver, A. M., and Rauschecker, J. P. (2010). Cortical representation of natural complex sounds: effects of acoustic features and auditory object category. J. Neurosci. 30, 7604-7612.

Lewis, J. W., Brefczynski, J. A., Phinney, R. E., Janik, J. J., and DeYoe, E. A. (2005). Distinct cortical pathways for processing tool versus animal sounds. J. Neurosci. 25, 5148-5158.

Lewis, J. W., Talkington, W. J., Walker, N. A., Spirou, G. A., Jajosky, A., Frum, C., and Brefczynski-Lewis, J. A. (2009). Human cortical organization for processing vocalizations indicates representation of harmonic structure as a signal attribute. J. Neurosci. 29, 2283-2296.

Liebenthal, E., Binder, J. R., Spitzer, S. M., Possing, E. T., and Medler, D.A. (2005). Neural substrates of phonemic perception. Cereb. Cortex 15, 1621-1631.

Lillywhite, L. M., Saling, M. M., Demutska, A., Masterton, R., Farquharson, S., and Jackson, G. D. (2010). The neural architecture of discourse compression. Neuropsychologia 48, 873-879.

Lockwood, A. H., Salvi, R. J., Coad, M. L., Arnold, S. A., Wack, D. S., Murphy, B. W., and Burkard, R. F. (1999). The functional anatomy of the normal human auditory system: responses to
0.5 and $4.0 \mathrm{kHz}$ tones at varied intensities. Cereb. Cortex 9, 65-76.

Maess, B., Koelsch, S., Gunter, T. C., and Friederici,A.D. (2001). Musical syntax is processed in Broca's area: an MEG study. Nat. Neurosci. 4, 540-545.

Müller, R. A., Behen, M. E., Rothermel, R. D., Chugani, D. C., Muzik, O., Mangner, T. J., and Chugani, H. T. (1999). Brain-mapping of language and auditory perception in high-functioning autistic adults: a PET study. J. Autism Dev. Disord. 29, 19-31.

Mummery, C. J., Ashburner, J., Scott, S. K., and Wise, R. J. S. (1999). Functional neuroimaging of speech perception in six normal and two aphasic subjects. $J$. Acoust. Soc. Am. 106, 449-457.

Mutschler, I., Wieckhorst, B., Speck, O., Schulze-Bonhage, A., Hennig, J., Seifritz, E., and Ball, T. (2010). Time scales of auditory habituation in the amygdala and cerebral cortex. Cereb. Cortex. 20, 2531-2539.

Narain, C., Scott, S. K., Wise, R. J., Rosen, S., Leff, A., Iversen, S. D., and Matthews, P. M. (2003). Defining a left-lateralized response specific to intelligible speech using fMRI. Cereb. Cortex 13, 1362-1368.

Obleser, J., Boecker, H., Drzezga, A., Haslinger, B., Hennenlotter, A., Roettinger, M., Eulitz, C., and Rauschecker, J.P. (2006). Vowel sound extraction in anterior superior temporal cortex. Hum. Brain Mapp. 27, 562-571.

Obleser, J., Eisner, F., and Kotz, S. A. (2008). Bilateral speech comprehension reflects differential sensitivity to spectral and temporal features. $J$. Neurosci. 28, 8116-8123.

Obleser, J.,Zimmermann, J., Van Meter, J., and Rauschecker,J.P. (2007). Multiple stages of auditory speech perception reflected in event-related FMRI. Cereb Cortex 17, 2251-2257.

Okada, K., Rong, F., Venezia, J., Matchin, W., Hsieh, I. H., Saberi, K., Serences, J. T., and Hickok, G. (2010). Hierarchical organization of human auditory cortex: evidence from acoustic invariance in the response to intelligible speech. Cereb. Cortex. 20, 2486-2495.

O'Leary, D., Andreasen, N. C., Hurtig, R. R., Hichwa, R. D., Watkins, L., Boles Ponto, L. L., Rogers, M., and Kirchner, P. T. (1996). A positron emission tomography study of binaurally and dichotically presented stimuli: effects of level of language and directed attention. Brain Lang. 53, 20-39.

Patterson, R. D., Uppenkamp, S., Johnsrude, I. S., and Griffiths, T. D. (2002). The processing of temporal pitch and melody information in auditory cortex. Neuron 36, 767-776.

Paulesu, E., Harrison, J., Bron-Cohen, S., Watson, J.D. G., Goldstein, L., Heather,
J., Frackowiak, R. S. J., and Frith, C. D. (1995). The physiology of coloured hearing. A PET activation study of colour-word synaesthesia, Brain 118, 661-676.

Peretz, I., Gosselin, N., Belin, P., Zatorre, R. J., Plailly, J., and Tillmann, B. (2009). Music lexical networks: the cortical organization of music recognition. Ann. N. Y. Acad. Sci. 1169, 256-265.

Petersen, S. E., Fox, P. T., Posner, M. I., Mintun, M., and Raichle, M.E. (1988). Positron emission tomographic studies of the cortical anatomy of single-word processing. Nature 331, 585-589.

Petkov, C. I., Kayser, C., Augath, M., and Logothetis, N. K. (2006). Functional imaging reveals numerous fields in the monkey auditory cortex. PLoS Biol. 4, e215. doi: 10.1371/journal. pbio.0040215

Petkov, C. I., Kayser, C., Steudel, T., Whittingstall, K., Augath, M., and Logothetis, N. K. (2008). A voice region in the monkey brain. Nat. Neurosci. 11,367-374.

Price, C., Wise, R., Ramsay, S., Friston, K., Howard, D. Patterson, K., and Frackowiak R. (1992). Regional response differences within the human auditory cortex when listening to words. Neurosci. Lett. 146, 179-182.

Rauschecker,J.P. (1998). Cortical processing of complex sounds. Curr. Opin. Neurobiol. 8, 516-521.

Rauschecker, J. P., and Scott, S. K. (2009). Maps and streams in the auditory cortex: nonhuman primates illuminate human speech processing. Nat. Neurosci. 12, 718-724.

Rauschecker, J. P., and Tian, B. (2000). Mechanisms and streams for processing of "what" and "where" in auditory cortex. Proc. Natl. Acad. Sci. U.S.A. 97, 11800-11806.

Rauschecker, J. P., and Tian, B. (2004). Processing of band-passed noise in the lateral auditory belt cortex of the rhesus monkey. J. Neurophysiol. 91, 2578-2589.

Rauschecker, J. P., Tian, B., and Hauser, M. (1995). Processing of complex sounds in the macaque nonprimary auditory cortex. Science 268, 111-114.

Recanzone, G. H., and Cohen, Y.E. (2010). Serial and parallel processing in the primate auditory cortex revisited. Behav. Brain Res. 206, 1-7.

Reynolds Losin, E. A., Rivera, S. M., O'Hare, E. D., Sowell, E. R., and Pinter, J. D. (2009). Abnormal fMRI activation pattern during story listening in individuals with Down syndrome. Am. J. Intellect. Dev. Disabil. 114, 369-380.

Rimol, L. M., Specht, K., Weis, S., Savoy, R., and Hugdahl, K. (2005). Processing of sub-syllabic speech units in the 
posterior temporal lobe: an fMRI study. Neuroimage 26, 1059-1067.

Rinne, T., Alho, K., Alku, P., Holi, M., Sinkkonen, J., Virtanen, J., Bertrand, O., and Näätänen, R.(1999).Analysis of speech sounds is left-hemisphere predominant at 100-150 ms after sound onset. Neuroreport 10, 1113-1117.

Rivier, F., and Clarke, S. (1997). Cytochrome oxidase, acetylcholinesterase, and NADPH-diaphorase staining in human supratemporal and insular cortex: evidence for multiple auditory areas. Neuroimage 6, 288-304.

Romanski, L. M., Tian, B., Fritz, J., Mishkin, M., Goldman-Rakic, P. S., and Rauschecker, J. P. (1999). Dual streams of auditory afferents target multiple domains in the primate prefrontal cortex. Nat. Neurosci. 2, 1131-1136.

Sabri, M., Binder, J. R., Desai, R., Medler, D. A., Leitl, M. D., and Liebenthal, E. (2008). Attentional and linguistic interactions in speech perception. Neuroimage 39, 1444-1456.

Schönwiesner, M., Novitski, N., Pakarinen, S., Carlson, S., Tervaniemi, M., and Naatanen, R. (2007). Heschl's gyrus, posterior superior temporal gyrus, and mid-ventrolateral prefrontal cortex have different roles in the detection of acoustic changes. J. Neurophysiol. 97, 2075-2082.

Schönwiesner, M., Rubsamen, R., and von Cramon, D. Y. (2005). Hemispheric asymmetry for spectral and temporal processing in the human antero-lateral auditory belt cortex. Eur. J. Neurosci. 22, 1521-1528.

Schönwiesner, M., and Zatorre, R. J. (2009).Spectro-temporal modulation transfer function of single voxels in the human auditory cortex measured with high-resolution fMRI. Proc. Natl. Acad. Sci. U.S.A. 106, 14611-14616.

Schwarzbauer, C., Davis, M. H., Rodd, J. M., and Johnsrude, I. (2006). Interleaved silent steady state (ISSS) imaging: a new sparse imaging method applied to auditory fMRI. Neuroimage $29,774-782$.

Scott, S. K., Blank, C. C., Rosen, S., and Wise, R. J. (2000). Identification of a pathway for intelligible speech in the left temporal lobe. Brain 123(Pt 12), 2400-2406.

Scott, S. K., and Johnsrude, I. S. (2003). The neuroanatomical and functional organization of speech perception. Trends Neurosci. 26, 100-107.

Shannon, R. V., Zeng, F. G., Kamath, V., Wygonski, J., and Ekelid, M.
(1995). Speech recognition with primarily temporal cues. Science 270, 303-304.

Shtyrov, Y., Kujala, T., Ahveninen, J., Tervaniemi, M., Alku, P., Ilmoniemi, R. J., and Näätänen, R. (1998). Background acoustic noise and the hemispheric lateralization of speech processing in the human brain: magnetic mismatch negativity study. Neurosci. Lett. 251, 141-144.

Specht, K., and Reul, J. (2003). Functional segregation of the temporal lobes into highly differentiated subsystems for auditory perception: an auditory rapid event-related fMRI-task. Neuroimage 20, 1944-1954.

Steinbrink, C., Ackermann, H., Lachmann, T., and Riecker, A. (2009). Contribution of the anterior insula to temporal auditory processing deficits in developmental dyslexia. Hum. Brain Mapp. 30, 2401-2411.

Stevens, A. A. (2004). Dissociating the cortical basis of memory for voices, words and tones. Brain Res. Cogn. Brain Res. 18, 162-171.

Sweet, R. A., Dorph-Petersen, K. A., and Lewis, D. A. (2005). Mapping auditory core, lateral belt, and parabelt cortices in the human superior temporal gyrus. J. Comp. Neurol. 491, 270-289.

Tervaniemi, M., and Hugdahl, K. (2003). Lateralization of auditory-cortex functions. Brain Res. Brain Res. Rev. $43,231-246$.

Thierry, G., Giraud, A. L., and Price, C. (2003). Hemispheric dissociation in access to the human semantic system. Neuron 38, 499-506.

Thivard, L., Belin, P., Zilbovicius, M., Poline, J. B., and Samson Y. (2000). A cortical region sensitive to auditory spectral motion. Neuroreport 11 , 2969-2972.

Tian, B., and Rauschecker, J. P. (1994). Processing of frequency-modulated sounds in the cat's anterior auditory field. J. Neurophysiol. 71, 1959-1975.

Tramo, M. J., Shah, G. D., and Braida, L. D. (2002). Functional role of auditory cortex in frequency processing and pitch perception. J. Neurophysiol. $87,122-139$.

Turkeltaub, P. E., Eden, G. F., Jones, K. M., and Zeffiro, T. A. (2002). Metaanalysis of the functional neuroanatomy of single-word reading: method and validation. Neuroimage 16(Pt 1), 765-780.

Uppenkamp, S., Johnsrude, I. S., Norris, D., Marslen-Wilson, W., and Patterson,
R. D. (2006). Locating the initial stages of speech-sound processing in human temporal cortex. Neuroimage 31 , 1284-1296.

Vouloumanos, A., Kiehl. K. A., Werker, J. F., and Liddle, P. F. (2001). Detection of sounds in the auditory stream: eventrelated fMRI evidence for differential activation to speech and nonspeech. $J$. Cogn. Neurosci. 13, 994-1005.

Wager, T. D., Lindquist, M. A., Nichols, T. E., Kober, H., and Van Snellenberg, J. X. (2009). Evaluating the consistency and specificity of neuroimaging data using meta-analysis. Neuroimage 45(Suppl.1), S210-S221.

Wallace, M. N., Johnston, P. W., and Palmer, A. R. (2002). Histochemical identification of cortical areas in the auditory region of the human brain. Exp. Brain Res. 143, 499-508.

Warren, J. D., and Griffiths, T. D. (2003). Distinct mechanisms for processing spatial sequences and pitch sequences in the human auditory brain, $J$. Neurosci. 23, 5799-5804.

Warren, J.D., Jennings, A. R., and Griffiths, T. D. (2005). Analysis of the spectral envelope of sounds by the human brain. Neuroimage 24, 1052-1057.

Warrier,C., Wong,P., Penhune, V.,Zatorre, R., Parrish, T., Abrams, D., and Kraus, N. (2009). Relating structure to function: Heschl's gyrus and acoustic processing. J. Neurosci. 29, 61-69.

Warrier, C. M., and Zatorre, R. J. (2002) Influence of tonal context and timbral variation on perception of pitch. Percept. Psychophys. 64, 198-207.

Warrier, C. M., and Zatorre, R. J. (2004). Right temporal cortex is critical for utilization of melodic contextual cues in a pitch constancy task. Brain $127(\mathrm{Pt}$ 7), 1616-1625.

Wessinger, C. M., VanMeter, J., Tian, B. Van Lare, J., Pekar, J., and Rauschecker, J. P. (2001). Hierarchical organization of the human auditory cortex revealed by functional magnetic resonance imaging. J. Cogn. Neurosci. $13,1-7$.

Wise, R., Chollet, F., Hadar, U., Friston, K. Hoffner, E., and Frackowiak, R. (1991) Distribution of cortical networks involved in word comprehension and word retrieval. Brain 114, 1803-1817.

Woods, D. L., and Alain, C. (2009). Functional imaging of human auditory cortex. Curr. Opin. Otolaryngol. Head Neck Surg. 17, 407-411.

Zaehle, T., Schimidt, C. F., Meyer, M., Baumann, S., Baltes, C., Boesiger, P., and Jancke, L. (2007). Comparison of "silent" clustered and sparse temporal fMRI acquisitions in tonal and speech perception tasks. Neuroimage 37, 1195-1204.

Zatorre, R. J., and Belin, P. (2001). Spectral and temporal processing in human auditory cortex. Cereb. Cortex 11 , 946-953.

Zatorre, R. J., Belin, P., and Penhune, V. B. (2002). Structure and function of auditory cortex: music and speech. Trends Cogn. Sci. 6, 37-46.

Zatorre, R. J., Bouffard, M., Ahad, P., and Belin, P. (2002). Where is 'where' in the human auditory cortex? Nat. Neurosci. 5, 905-909.

Zatorre, R. J., Evans, A. C., and Meyer E. (1994). Neural mechanisms underlying melodic perception and memory for pitch. J. Neurosci. 14 , 1908-1919.

Zatorre, R. J., Evans, A. C., Meyer, A., and Gjedde,A. (1992).Lateralization of phonetic and pitch discrimination in speech processing. Science 256, 846-849.

Zatorre, R. J., Meyer, E, Gjedde, A., and Evans, A. C. (1996). PET studies of phonetic processing of speech: review, replication and reanalysis. Cereb. Cortex 6, 21-30.

Zevin, J., and McCandliss, B. (2005). Dishabituation of the BOLD response to speech sounds. Behav. Brain Funct. 1,4 .

Conflict of Interest Statement: The authors declare that the research was conducted in the absence of any commercial or financial relationships that could be construed as a potential conflict of interest.

Received: 16 September 2010; accepted: 23 December 2010; published online: 17 January 2011.

Citation: Samson F, Zeffiro TA, Toussaint A and Belin P (2011) Stimulus complexity and categorical effects in human auditory cortex: an Activation Likelihood Estimation meta-analysis. Front. Psychology 1:241. doi: 10.3389/fpsyg.2010.00241

This article was submitted to Frontiers in Auditory Cognitive Neuroscience, a specialty of Frontiers in Psychology.

Copyright () 2011 Samson, Zeffiro, Toussaint and Belin. This is an openaccess article subject to an exclusive license agreement between the authors and the Frontiers Research Foundation, which permits unrestricted use, distribution, and reproduction in any medium, provided the original authors and source are credited. 


\section{APPENDIX}

Table A1 | Selection of foci for the subsamples: Vocal sounds (20 contrasts, 165 foci) Intelligible speech (27 contrasts, 166 foci), Complex non-speech (13 contrasts, 76 foci) and Multiple frequency, irregular change (10 contrasts, 70 foci).

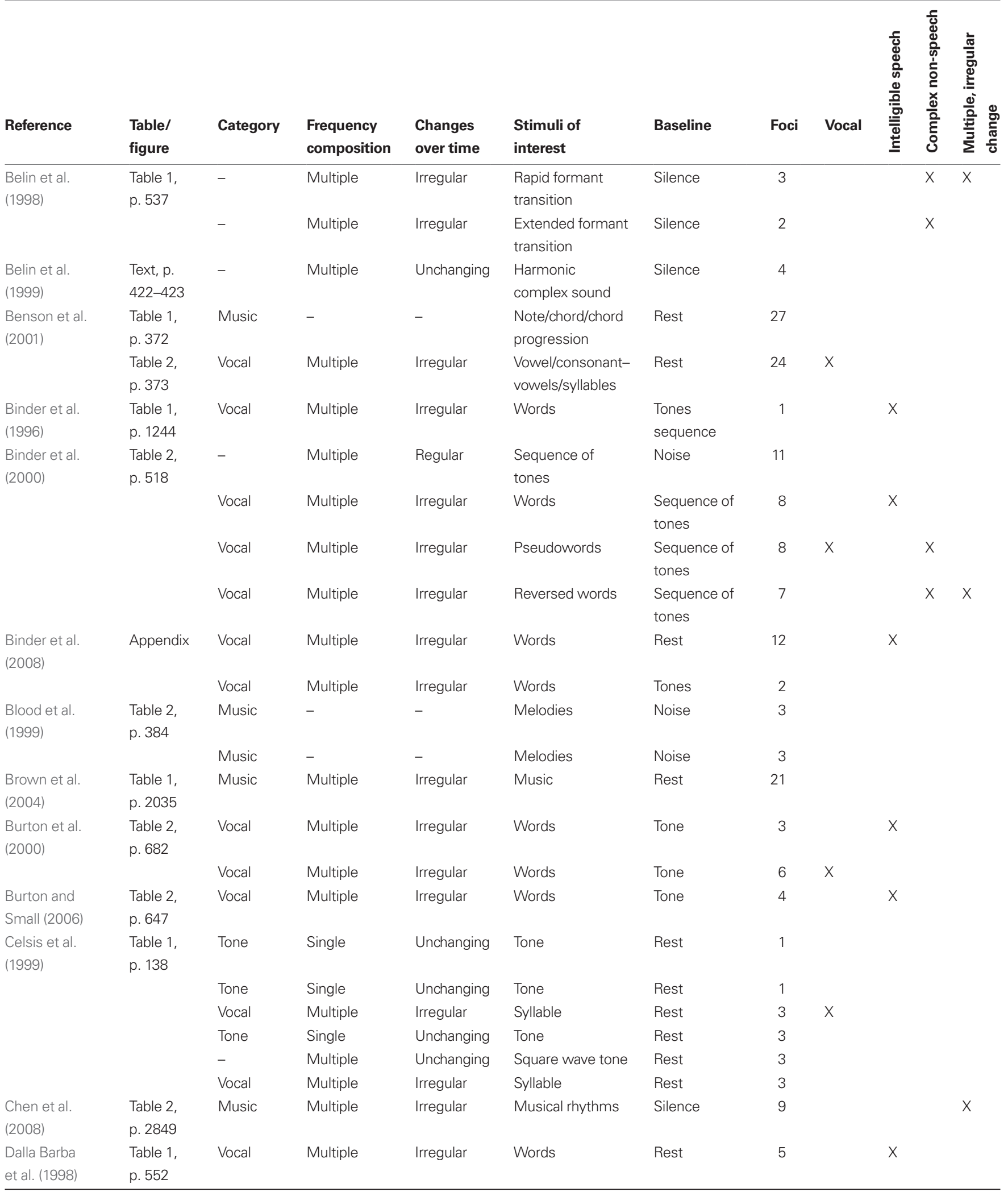




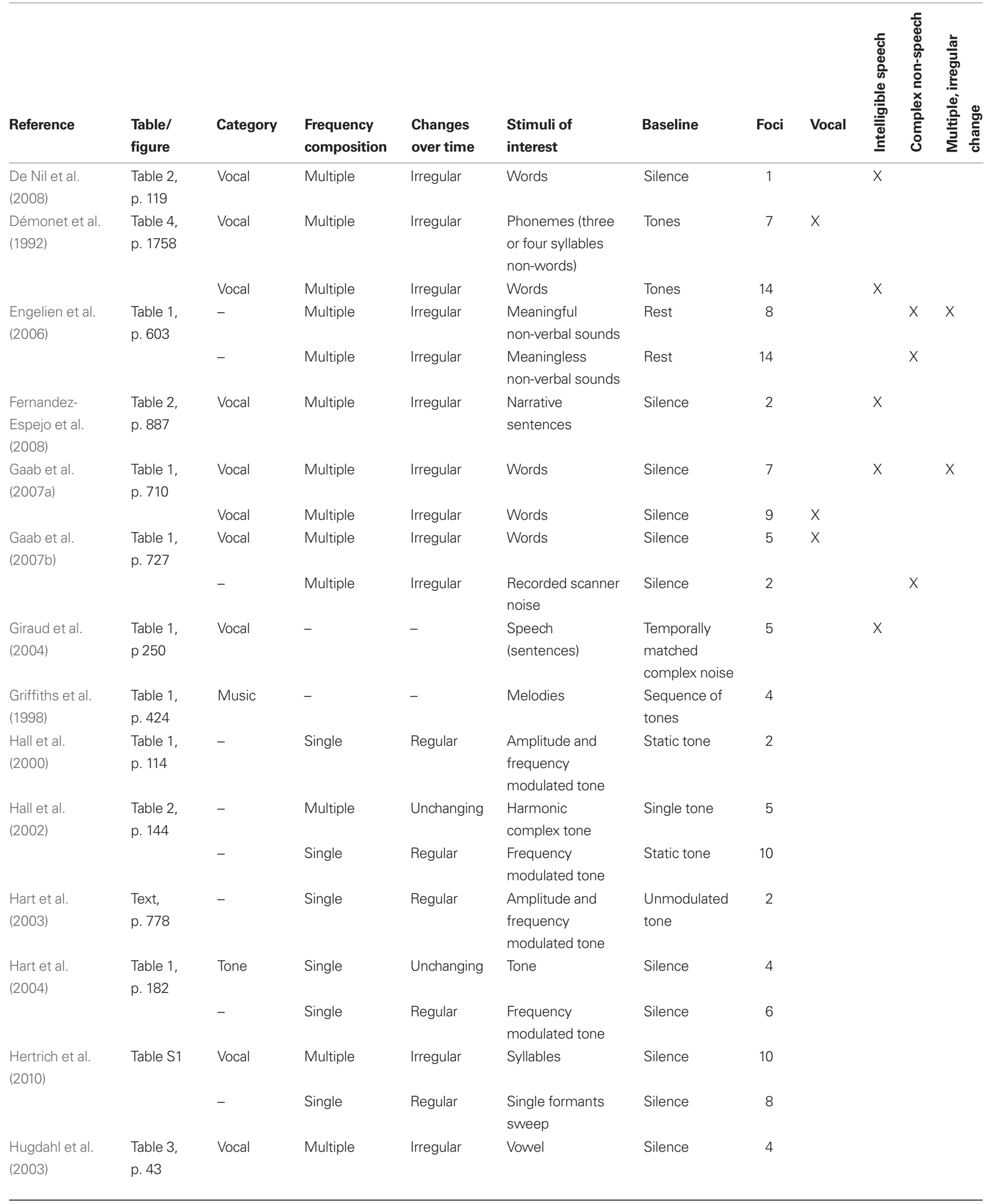




\begin{tabular}{|c|c|c|c|c|c|c|c|c|c|c|c|}
\hline Reference & $\begin{array}{l}\text { Table/ } \\
\text { figure }\end{array}$ & Category & $\begin{array}{l}\text { Frequency } \\
\text { composition }\end{array}$ & $\begin{array}{l}\text { Changes } \\
\text { over time }\end{array}$ & $\begin{array}{l}\text { Stimuli of } \\
\text { interest }\end{array}$ & Baseline & Foci & Vocal & 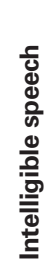 & 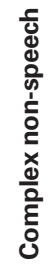 & 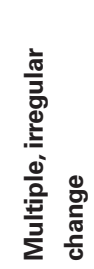 \\
\hline & $\begin{array}{l}\text { Table 5, } \\
\text { p. } 43\end{array}$ & Vocal & Multiple & Irregular & Words & Silence & 2 & & $x$ & & \\
\hline $\begin{array}{l}\text { Hwang et al. } \\
\text { (2007) }\end{array}$ & $\begin{array}{l}\text { Table 2, } \\
\text { p. } 289\end{array}$ & Vocal & Multiple & Irregular & Sentences & Quiet & 7 & & $X$ & & $x$ \\
\hline \multirow[t]{3}{*}{$\begin{array}{l}\text { Jäncke et al. } \\
\text { (1998) }\end{array}$} & $\begin{array}{l}\text { Table 1, } \\
\text { p. } 878\end{array}$ & Vocal & Multiple & Irregular & Syllables & Silence & 9 & $x$ & & & \\
\hline & & - & Multiple & Regular & Tone sequence & Silence & 6 & & & & \\
\hline & & - & Multiple & Regular & Tone sequence & Silence & 6 & & & & \\
\hline $\begin{array}{l}\text { Lillywhite et al. } \\
\text { (2010) }\end{array}$ & $\begin{array}{l}\text { Table 1, } \\
\text { p. } 875\end{array}$ & Vocal & Multiple & Irregular & Story listening & White noise & 2 & $x$ & $X$ & & \\
\hline \multirow[t]{2}{*}{$\begin{array}{l}\text { Müller et al. } \\
\text { (1999) }\end{array}$} & $\begin{array}{l}\text { Table 3, } \\
\text { p. } 24\end{array}$ & - & Multiple & Regular & $\begin{array}{l}\text { Sequence of } \\
\text { tones }\end{array}$ & Rest & 6 & & & & \\
\hline & & Vocal & Multiple & Irregular & Sentences & Rest & 5 & $x$ & $x$ & & \\
\hline $\begin{array}{l}\text { Mummery } \\
\text { et al. (1999) }\end{array}$ & $\begin{array}{l}\text { Table 1, } \\
\text { p. } 452\end{array}$ & Vocal & - & - & Speech (words) & $\begin{array}{l}\text { Signal } \\
\text { correlated } \\
\text { noise }\end{array}$ & 7 & & $x$ & & \\
\hline $\begin{array}{l}\text { Mutschler et al. } \\
\text { (2010) }\end{array}$ & $\begin{array}{l}\text { Supp. } \\
\text { Material }\end{array}$ & Music & Multiple & Irregular & Melodies & Rest & 94 & & & & \\
\hline $\begin{array}{l}\text { Peretz et al. } \\
\text { (2009) }\end{array}$ & $\begin{array}{l}\text { Table 1, } \\
\text { p. } 263\end{array}$ & Music & - & - & Melodies & $\begin{array}{l}\text { Random tone } \\
\text { sequence }\end{array}$ & 8 & & & & \\
\hline $\begin{array}{l}\text { Petersen et al. } \\
\text { (1988) }\end{array}$ & $\begin{array}{l}\text { Table 2, } \\
\text { p. } 585\end{array}$ & Vocal & Multiple & Irregular & Words & $\begin{array}{l}\text { Silence } \\
\text { (fixation point) }\end{array}$ & 6 & & $X$ & & \\
\hline $\begin{array}{l}\text { Price et al. } \\
\text { (1992) }\end{array}$ & $\begin{array}{l}\text { Figure 1, } \\
\text { p. } 180\end{array}$ & Vocal & Multiple & Irregular & Nouns & Rest & 6 & $x$ & $X$ & & \\
\hline $\begin{array}{l}\text { Reynolds Losin } \\
\text { et al. (2009) }\end{array}$ & $\begin{array}{l}\text { Table 1, } \\
\text { p. } 374\end{array}$ & Vocal & Multiple & Irregular & Story listening & Rest & 3 & & $x$ & & \\
\hline \multirow[t]{6}{*}{$\begin{array}{l}\text { Rimol et al. } \\
\text { (2005) }\end{array}$} & $\begin{array}{l}\text { Table 1, } \\
\text { p. } 1063\end{array}$ & Vocal & Multiple & Irregular & Consonant & Rest & 8 & $x$ & & & \\
\hline & & Vocal & Multiple & Irregular & Syllables & Rest & 6 & & & & \\
\hline & & Noise & Multiple & Unchanging & $\begin{array}{l}\text { Noise (white, } \\
\text { brown, pink) }\end{array}$ & Rest & 12 & & & & \\
\hline & & Noise & Multiple & Unchanging & $\begin{array}{l}\text { Noise (white, } \\
\text { brown, pink) }\end{array}$ & Rest & 8 & & & & \\
\hline & $\begin{array}{l}\text { Table 2, } \\
\text { p. } 1064\end{array}$ & Vocal & Multiple & Irregular & Consonant & Noise & 1 & & & & \\
\hline & & Vocal & Multiple & Irregular & Syllable & Noise & 3 & & & & \\
\hline
\end{tabular}




\begin{tabular}{|c|c|c|c|c|c|c|c|c|c|c|c|}
\hline Reference & $\begin{array}{l}\text { Table/ } \\
\text { figure }\end{array}$ & Category & $\begin{array}{l}\text { Frequency } \\
\text { composition }\end{array}$ & $\begin{array}{l}\text { Changes } \\
\text { over time }\end{array}$ & $\begin{array}{l}\text { Stimuli of } \\
\text { interest }\end{array}$ & Baseline & Foci & Vocal & 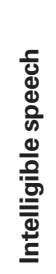 & 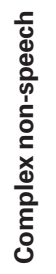 & 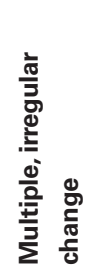 \\
\hline & & Vocal & - & - & Sentences & $\begin{array}{l}\text { Signal } \\
\text { correlated } \\
\text { noise }\end{array}$ & 6 & & & & \\
\hline $\begin{array}{l}\text { Schönwiesner } \\
\text { et al. (2005) }\end{array}$ & $\begin{array}{l}\text { Text, p. } \\
1523- \\
1525\end{array}$ & - & Single & Regular & $\begin{array}{l}\text { Parametric } \\
\text { increase in } \\
\text { temporal rate } \\
\text { change }\end{array}$ & Silence & 2 & & & & \\
\hline \multirow[t]{5}{*}{$\begin{array}{l}\text { Specht and } \\
\text { Reul (2003) }\end{array}$} & $\begin{array}{l}\text { Table 1, } \\
\text { p. } 1950\end{array}$ & Tone & Single & Unchanging & Tones & Rest & 5 & & & & \\
\hline & & - & Multiple & Irregular & $\begin{array}{l}\text { Sounds of animal } \\
\text { and instruments }\end{array}$ & Rest & 9 & & & $x$ & $x$ \\
\hline & & Vocal & Multiple & Irregular & Words & Rest & 18 & $x$ & $x$ & & \\
\hline & $\begin{array}{l}\text { Table 2, } \\
\text { p. } 1951\end{array}$ & - & Multiple & Irregular & $\begin{array}{l}\text { Sounds of animal } \\
\text { and instruments }\end{array}$ & Tones & 7 & & & $x$ & \\
\hline & & Vocal & Multiple & Irregular & Words & Tones & 12 & & & & \\
\hline \multirow[t]{3}{*}{$\begin{array}{l}\text { Thivard et al. } \\
(2000)\end{array}$} & $\begin{array}{l}\text { Table 1, } \\
\text { p. } 2971\end{array}$ & - & Multiple & Unchanging & $\begin{array}{l}\text { Static complex } \\
\text { sound }\end{array}$ & Silence & 6 & & & & \\
\hline & & - & Multiple & Irregular & $\begin{array}{l}\text { Complex sound } \\
\text { modulated } \\
\text { (motion) }\end{array}$ & Silence & 6 & & & $x$ & \\
\hline & & - & Single & Irregular & $\begin{array}{l}\text { Complex sound } \\
\text { modulated } \\
\text { (motion) }\end{array}$ & $\begin{array}{l}\text { Static } \\
\text { complex } \\
\text { sound }\end{array}$ & 4 & & & & \\
\hline \multirow[t]{2}{*}{$\begin{array}{l}\text { Vouloumanos } \\
\text { et al. (2001) }\end{array}$} & $\begin{array}{l}\text { Table 1, } \\
\text { p. } 998\end{array}$ & Vocal & Multiple & Irregular & Words & Tones & 8 & & $x$ & & \\
\hline & & - & Multiple & Irregular & $\begin{array}{l}\text { Non-speech } \\
\text { complex } \\
\text { sinewave sounds }\end{array}$ & Tones & 5 & & & $x$ & $x$ \\
\hline $\begin{array}{l}\text { Warren and } \\
\text { Griffiths (2003) }\end{array}$ & $\begin{array}{l}\text { Table 1, } \\
\text { p. } 5802\end{array}$ & Music & - & - & $\begin{array}{l}\text { Changing pitch } \\
\text { sequences }\end{array}$ & $\begin{array}{l}\text { Fixed pitch } \\
\text { sequences }\end{array}$ & 4 & & & & \\
\hline $\begin{array}{l}\text { Warrier et al. } \\
\text { (2009) }\end{array}$ & $\begin{array}{l}\text { Table 2, } \\
\text { p. } 65\end{array}$ & - & Single & Regular & $\begin{array}{l}\text { Parametric } \\
\text { increase in } \\
\text { temporal rate } \\
\text { change }\end{array}$ & Silence & 6 & & & & \\
\hline
\end{tabular}




\begin{tabular}{|c|c|c|c|c|c|c|c|c|c|c|c|}
\hline Reference & $\begin{array}{l}\text { Table/ } \\
\text { figure }\end{array}$ & Category & $\begin{array}{l}\text { Frequency } \\
\text { composition }\end{array}$ & $\begin{array}{l}\text { Changes } \\
\text { over time }\end{array}$ & $\begin{array}{l}\text { Stimuli of } \\
\text { interest }\end{array}$ & Baseline & Foci & Vocal & 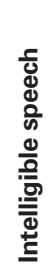 & 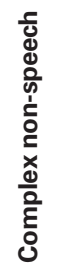 & 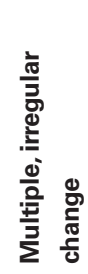 \\
\hline $\begin{array}{l}\text { Wise et al. } \\
\text { (1991) }\end{array}$ & $\begin{array}{l}\text { Table 2, } \\
\text { p. } 1808\end{array}$ & Vocal & Multiple & Irregular & Nouns & Rest & 6 & $x$ & $x$ & & \\
\hline \multirow[t]{8}{*}{$\begin{array}{l}\text { Zaehle et al. } \\
\text { (2007) }\end{array}$} & $\begin{array}{l}\text { Table 1, } \\
\text { p. } 1201\end{array}$ & Vocal & Multiple & Irregular & Sentences & Silence & 2 & & $x$ & & \\
\hline & & Vocal & Multiple & Irregular & Sentences & Tones & 2 & & & & \\
\hline & $\begin{array}{l}\text { Table 2, } \\
\text { p. } 1201\end{array}$ & Vocal & Multiple & Irregular & Sentences & Silence & 2 & & & & \\
\hline & & Vocal & Multiple & Irregular & Sentences & Silence & 2 & & & & \\
\hline & & Tone & Single & Unchanging & Tones & Silence & 2 & & & & \\
\hline & & Tone & Single & Unchanging & Tones & Silence & 2 & & & & \\
\hline & & Vocal & Multiple & Irregular & Sentences & Tones & 2 & & & & \\
\hline & & Vocal & Multiple & Irregular & Sentences & Tones & 2 & & & & \\
\hline \multirow[t]{2}{*}{$\begin{array}{l}\text { Zatorre et al. } \\
\text { (1992) }\end{array}$} & $\begin{array}{l}\text { Table 2, } \\
\text { p. } 847\end{array}$ & Noise & Multiple & Unchanging & $\begin{array}{l}\text { White noise } \\
\text { bursts }\end{array}$ & Silence & 8 & & & & \\
\hline & & Vocal & Multiple & Irregular & Syllables & Noise & 6 & $x$ & & & \\
\hline & & - & Multiple & Unchanging & $\begin{array}{l}\text { Tone sequence } \\
\text { with increasing } \\
\text { number of } \\
\text { spectral elements }\end{array}$ & Silence & 3 & & & & \\
\hline $\begin{array}{l}\text { Zevin and } \\
\text { McCandliss } \\
\text { (2005) }\end{array}$ & Table 1 & Vocal & Multiple & Irregular & Syllables & Silence & 8 & $x$ & & & $x$ \\
\hline
\end{tabular}

